\title{
CD28-dependent Rac1 activation is the molecular target of azathioprine in primary human $\mathrm{CD4}^{+} \mathrm{T}$ lymphocytes
}

\author{
Imke Tiede, ${ }^{1}$ Gerhard Fritz, ${ }^{2}$ Susanne Strand, ${ }^{1}$ Daniela Poppe, ${ }^{1}$ Radovan Dvorsky, ${ }^{3}$ \\ Dennis Strand, ${ }^{1}$ Hans Anton Lehr, ${ }^{4}$ Stefan Wirtz, ${ }^{1}$ Christoph Becker, ${ }^{1}$ Raja Atreya, ${ }^{1}$ \\ Jonas Mudter, ${ }^{1}$ Kai Hildner, ${ }^{1}$ Brigitte Bartsch, ${ }^{1}$ Martin Holtmann, ${ }^{1}$ Richard Blumberg, ${ }^{5}$ \\ Henning Walczak, ${ }^{6}$ Heiko Iven, ${ }^{7}$ Peter R. Galle, ${ }^{1}$ Mohammad Reza Ahmadian, ${ }^{3}$ \\ and Markus F. Neurath ${ }^{1}$
}

${ }^{1}$ Laboratory of Immunology, Department of Medicine, and

${ }^{2}$ Department of Toxicology, University of Mainz, Mainz, Germany

${ }^{3}$ Max Planck Institute of Molecular Physiology, Dortmund, Germany

${ }^{4}$ Department of Pathology, University of Mainz, Mainz, Germany

${ }^{5}$ Brigham and Women's Hospital, Gastroenterology Division, Harvard Medical School, Boston, Massachusetts, USA

${ }^{6}$ Division of Apoptosis Regulation, Tumor Immunology Program, German Cancer Research Center, Heidelberg, Germany

${ }^{7}$ Department of Pharmacology, University of Lübeck, Lübeck, Germany

Azathioprine and its metabolite 6-mercaptopurine (6-MP) are immunosuppressive drugs that are used in organ transplantation and autoimmune and chronic inflammatory diseases such as Crohn disease. However, their molecular mechanism of action is unknown. In the present study, we have identified a unique and unexpected role for azathioprine and its metabolites in the control of $\mathrm{T}$ cell apoptosis by modulation of Rac1 activation upon CD28 costimulation. We found that azathioprine and its metabolites induced apoptosis of $\mathrm{T}$ cells from patients with Crohn disease and control patients. Apoptosis induction required costimulation with $\mathrm{CD} 28$ and was mediated by specific blockade of Rac1 activation through binding of azathioprine-generated 6-thioguanine triphosphate (6-Thio-GTP) to Rac1 instead of GTP. The activation of Rac1 target genes such as mitogen-activated protein kinase kinase (MEK), NF- $\kappa B$, and $b c l-x_{L}$ was suppressed by azathioprine, leading to a mitochondrial pathway of apoptosis. Azathioprine thus converts a costimulatory signal into an apoptotic signal by modulating Rac1 activity. These findings explain the immunosuppressive effects of azathioprine and suggest that 6-Thio-GTP derivates may be useful as potent immunosuppressive agents in autoimmune diseases and organ transplantation.

J. Clin. Invest. 111:1133-1145 (2003). doi:10.1172/JCI200316432.

\section{Introduction}

Azathioprine and its metabolite 6-mercaptopurine (6-MP) are widely used as immunosuppressive and

Received for publication July 16, 2002, and accepted in revised form January 28, 2003.

Address correspondence to: Markus F. Neurath, Laboratory of Immunology, Department of Medicine, University of Mainz, Langenbeckstrasse 1, 55101 Mainz, Germany.

Phone: 49-6131-172489; Fax: 49-6131-175508;

E-mail: neurath@1-med.klinik.uni-mainz.de.

Conflict of interest: The authors have declared that no conflict of interest exists.

Nonstandard abbreviations used: 6-mercaptopurine (6-MP); 6-thioguanine triphosphate (6-Thio-GTP); inflammatory bowel disease (IBD); thiopurine S-methyltransferase (TPMT); hypoxanthine phosphoribosyl transferase (HPRT); 6-thioguanine (6-TG); peripheral blood mononuclear cell (PBMC); lamina propria mononuclear cell (LPMC); calcium- and magnesium-free HBSS (HBSS-CMF); T cell receptor (TCR); mitogen-activated protein kinase kinase (MEK); signal transducer and activator of transcription-3 (STAT-3); electrophoretic mobility shift assay (EMSA); mitochondrial membrane potential $\left(\Delta \Psi_{\mathrm{m}}\right)$; carbonylcyanide-4-(trifluoromethoxy)-phenylhydrazone (FCCP); MEK kinase (MEKK); recombinant IL-2 (rIL-2). anti-inflammatory agents in organ transplantation and the treatment of chronic inflammatory diseases. For instance, azathioprine has been therapeutically used in kidney (1) and heart (2) transplantation and various autoimmune and chronic inflammatory diseases, such as multiple sclerosis (3), rheumatoid arthritis (4), systemic lupus erythematosus (5), primary biliary cirrhosis (6), and inflammatory bowel diseases (IBDs) (7-11). Although azathioprine has been in clinical use for about four decades (12), its precise mechanisms of action are still unknown. However, inhibition of purine nucleotide biosynthesis with suppression of DNA and RNA synthesis and downregulation of B and $T$ cell function have been suggested as major therapeutic mechanisms (13-17).

The azathioprine molecule is composed of two moieties: mercaptopurine and an imidazole derivative (14, 18). After oral administration and absorption, the prodrug azathioprine undergoes approximately $90 \%$ conversion to 6-MP by nonenzymatic attack by sulphydrylcontaining compounds such as glutathione or cysteine that are present in every mammalian cell $(14,19)$. 6-MP 
is then enzymatically converted by xanthine oxidase to 6-thiouric acid, by thiopurine S-methyltransferase (TPMT) to 6-methyl-MP, and by hypoxanthine phosphoribosyl transferase (HPRT) to 6-thioguanine (6-TG). Whereas the TPMT pathway appears to be important for azathioprine-mediated side effects such as myelosuppression, the 6-TG generated by the HPRT pathway most likely mediates the immunosuppressive properties of 6-MP (14). In particular, lymphocytes have been shown to enzymatically convert 6-MP to 6-TG (20).

Crohn disease is a major form of IBD leading to a chronic granulomatous inflammation that can occur anywhere in the alimentary tract (21). Although the precise pathogenesis is still unknown, recent data suggest that genetic factors (e.g., NOD2 mutations), environmental factors (e.g., bacterial antigens), and an activation of the mucosal immune system play a major pathogenic role (21-29). In the chronic phase of this disease, cytokines produced by macrophages and $\mathrm{T}$ lymphocytes in the lamina propria have been shown to play a key pathogenic role (30-32). In particular, it has recently been demonstrated that proinflammatory cytokines such as IL- 6 and IL-12 may cause T cell resistance against apoptosis in Crohn disease that leads to inappropriate lymphocyte accumulation in the gut and disease perpetuation $(30,33)$.

Azathioprine is considered the gold standard of immunosuppressive therapy for Crohn disease $(11,34)$. Interestingly, it has been shown that patients with Crohn disease who were treated with azathioprine for only a few weeks did not respond to therapy, suggesting that this drug requires prolonged periods of time to achieve clinical responses $(35,36)$. Furthermore, a recent meta-analysis demonstrated that the odds ratio of response to azathioprine in this disease increased with the cumulative dose administered (35). Although azathioprine has been in clinical use for IBD for about four decades (12), its precise mechanism of action is still unknown (14).

In the present study, we focused on the potential mechanism of action of azathioprine in T lymphocytes. We observed that the small GTPase Rac1 is the molecular target for the azathioprine metabolite 6-thioguanine triphosphate (6-Thio-GTP). Azathioprine thus appears to induce immunosuppression by inhibiting Rac1 activation in T cells.

\section{Methods}

Isolation of primary $C D 4^{+} T$ lymphocytes and lamina propria cells. Human peripheral blood mononuclear cells (PBMCs) from healthy volunteers (25-42 years of age) and patients with Crohn disease (31-65 years of age) were isolated using Ficoll-Hypaque gradients. PBMCs were further purified using CD4 monoclonal antibodies attached to immunomagnetic beads according to the manufacturer's protocol, followed by treatment with Detachabead (Dynal, Oslo, Norway). In some cases, $\mathrm{CD}^{+} \mathrm{T}$ cells were further separated by negative selection techniques using CD45RO or CD45RA monoclonal antibodies (PharMingen, Heidelberg, Germany) and immunomagnetic beads (Dynal). Reanalysis of sorted populations revealed a purity of over 96\%. Lamina propria mononuclear cells (LPMCs) from patients with IBD were isolated from gut specimens using a short-term (5-minute) digestion protocol with collagenase $\mathrm{V}$, hyaluronidase (Sigma-Aldrich, St. Louis, Missouri, USA), and DNase (Roche, Mannheim, Germany), as recently described in detail elsewhere (37). Briefly, specimens were washed in calcium- and magnesium-free HBSS (HBSS-CMF), cut into $0.5-\mathrm{cm}$ pieces, and incubated twice in HBSS containing EDTA $(0.37 \mathrm{mg} / \mathrm{ml})$ and DTT $(0.145 \mathrm{mg} / \mathrm{ml})$ at $37^{\circ} \mathrm{C}$ for 15 minutes, followed by subsequent digestion for 5 minutes with collagenase V $400(1 \mathrm{mg} / \mathrm{ml})$, deoxyribonuclease $(0.1 \mathrm{mg} / \mathrm{ml}$ DNase $)$, and hyaloronidase $(0.1 \mathrm{mg} / \mathrm{ml})$ in a shaking incubator at $37^{\circ} \mathrm{C}$. The digested tissue was washed twice in RPMI medium containing $10 \%$ FCS and centrifuged. The tissue was finally mechanically homogenized (DAKO homogenizer, Hamburg, Germany) for 4 minutes, and cells were filtered through a sterile $40-\mu \mathrm{m}$ cell strainer (Falcon, San Diego, California, USA). The cells were then cultured in the presence or absence of azathioprine, as specified below.

Cell culture and stimulation conditions. Cell cultures of $T$ cells were performed in complete medium consisting of RPMI-1640 (Biochrom KG, Berlin, Germany) supplemented with $3 \mathrm{mM}$ L-glutamine (Whittaker, Walkersville, Maryland, USA), $100 \mathrm{U} / \mathrm{ml}$ each of penicillin and streptomycin (Whittaker), and 10\% heat-inactivated FCS (PAA Laboratories, Linz, Austria).

$T$ cell stimulation for the analysis of azathioprine- and 6-MP-induced apoptosis. T lymphocytes were stimulated in cell culture for 3-5 days (as specified in Results) with coated antibodies to CD3 $(0.04 \mu \mathrm{g} / \mathrm{ml}$ HIT3a, PharMingen $)$ and soluble CD28 antibodies $(1 \mu \mathrm{g} / \mathrm{ml}$, PharMingen). Such CD28 costimulation is known to prevent apoptosis of primary $\mathrm{T}$ cells during $\mathrm{T}$ cell receptor (TCR) stimulation through activation of bcl- $\mathrm{x}_{\mathrm{L}}$ and NF- $\mathrm{\kappa B}(38-40)$. In our experimental system, we observed no further increase in $\mathrm{T}$ cell proliferation upon administration of 10 - or even 100 -fold increased dosages of anti-CD3 antibodies (mean values of three experiments: no anti-CD, 138,667 cpm; $0.004 \mu \mathrm{g} / \mathrm{ml}$, $296,500 \mathrm{cpm} ; 0.4 \mu \mathrm{g} / \mathrm{ml}, 306,333 \mathrm{cpm} ; 4 \mu \mathrm{g} / \mathrm{ml}$, $348,500 \mathrm{cpm})$, which strongly suggests that the antiCD3 dosage that we used is optimal and that there is a true CD28-dependent effect on Rac1 and NF- $\mathrm{BB}$ activation. In addition, recombinant IL-2 (R\&D Systems, Wiesbaden, Germany) was used at a final concentration of $40 \mathrm{U} / \mathrm{ml}$ in all experiments. Lamina propria $\mathrm{T}$ lymphocytes were stimulated with antibodies to CD2 (4 $\mu \mathrm{g} / \mathrm{ml}$; Immunotech, Marseille, France) and CD28 (1 $\mu \mathrm{g} / \mathrm{ml}$ ). Azathioprine, 6-MP, and 6-TG (SigmaAldrich) were added to the $T$ cell cultures at indicated concentrations and time points. To block CD95Lmediated (FasL-mediated) apoptosis, the NOK-1 antibody ( $4 \mu \mathrm{g} / \mathrm{ml}$, PharMingen) was used whose Fab frag- 
ments bind to human CD95L (FasL) (41). Recombinant human FasL (Alexis Biochemicals, Heidelberg, Germany) was used as positive control for the NOK-1 antibody $(10 \mu \mathrm{g} / \mathrm{ml})$ (data not shown).

Analysis of T cell vitality and clonal expansion. To induce $\mathrm{T}$ cell expansion, purified $\mathrm{T}$ lymphocytes were stimulated with coated antibodies to CD3 $(0.04 \mu \mathrm{g} / \mathrm{ml})$, soluble antibodies to CD28 $(1 \mu \mathrm{g} / \mathrm{ml})$, and recombinant IL-2 $(40 \mathrm{U} / \mathrm{ml})$ for the indicated periods of time. Stimulated $\mathrm{T}$ lymphocytes were cultured in the presence or absence of azathioprine or 6-MP (Sigma-Aldrich), as specified in the Results. Cell viability was assessed by trypan blue (Sigma-Aldrich) staining at the beginning and at the end of the cell culture. The clonal expansion of $T$ cells during cell culture was calculated by the ratio between cell numbers at the beginning and at the end of the cell culture.

FACS analysis. Analysis of peripheral blood T cells and lamina propria $\mathrm{T}$ lymphocytes by FACS (FACSscan, Becton Dickinson, Berlin, Germany) was performed using FITC-labeled murine antibodies to human CD4 (PharMingen), anti-mouse IgG1 isotype control antibodies (PharMingen), antibodies to bcl- $\mathrm{x}_{\mathrm{L}}$ and $\mathrm{p}$ mitogen-activated protein kinase kinase (pMEK) (Santa Cruz Biotech, Santa Cruz, California, USA), and goat anti-mouse Fab-FITC (DAKO). For intracellular staining analysis, $\mathrm{T}$ cells were fixed in PBS/4\% paraformaldehyde (Merck, Munich, Germany) for 10 minutes at $4^{\circ} \mathrm{C}$, washed twice in PBS, permeabilized in PBS $/ 0.1 \%$ Triton X-100 (Sigma-Aldrich, Steinheim, Germany), and treated with mouse anti-human bcl- $\mathrm{x}_{\mathrm{L}}$ or MEK antibodies $\left(2 \mu \mathrm{g}\right.$ per $5 \times 10^{5}$ cells) for 30 minutes on ice. $\mathrm{T}$ cells were washed twice in PBS/0.1\% Triton X-100 before incubation with goat anti-mouse Fab-FITC $(2 \mu \mathrm{l}$ per $10^{5}$ cells). Finally, T cells were washed twice in PBS before FACS analysis.

Analysis of cell apoptosis by annexin $V$ staining and by staining according to Nicoletti. To determine induction of apoptosis in primary $\mathrm{T}$ lymphocytes, cells were coincubated with the indicated amounts of azathioprine, 6-MP, or 6-TG as specified in Results and then analyzed by FACS. For FACS analysis, apoptotic cells were detected by staining with annexin $\mathrm{V}$ and propidium iodide using the Annexin V FITC Apoptosis Detection Kit I (PharMingen) (30). In brief, T cells were washed twice in PBS, and the pellet was resuspended in annexin $\mathrm{V}$ binding buffer (PharMingen) at a concentration of $10^{6}$ cells per milliliter. Annexin V FITC and propidium iodide were added ( $5 \mu \mathrm{l}$ of each per $10^{5}$ cells). Samples were gently mixed and incubated for 15 minutes at room temperature in the dark before FACS analysis. To verify the results obtained with the annexin $\mathrm{V} /$ propidium iodide staining, analysis of $\mathrm{T}$ cells displaying DNA fragmentation was also determined by the Nicoletti technique, as previously described in detail (42). $10^{6} \mathrm{~T}$ cells were fixed in $70 \%$ ethanol, washed once in HBSS, resuspended in $1 \mathrm{ml}$ of HBSS and $1 \mathrm{ml}$ of phosphate citric acid buffer $(0.2 \mathrm{~mol} / 1$ $\mathrm{Na}_{2} \mathrm{PO}_{4}$ and $0.004 \mathrm{~mol} / \mathrm{l}$ citric acid [pH 7.8]), and incubated at room temperature for 5 minutes. After centrifugation, cells were resuspended in $1 \mathrm{ml}$ of HBSS containing $20 \mu \mathrm{g} / \mathrm{ml}$ propidium iodide and 10 U DNase-free RNase A and incubated at room temperature for 30 minutes. Finally, cells were analyzed on a FACScan flow cytometer. Because of the fragmentation of DNA, apoptotic cells appear as hypodiploid in the DNA histogram.

Analysis of cellular apoptosis by transmission electron microscopy. For transmission electron microscopy, cells were coincubated with 6-MP $(5 \mu \mathrm{M})$, washed in PBS, and fixed in $2.5 \%$ glutaraldehyde ( $\mathrm{pH} 7.2$ ) overnight. Cells were postfixed in $1 \%$ osmium tetroxide for 2 hours and dehydrated in graded ethanol. After transfer to propylene oxide, the cells were finally embedded in agar 100 resin (Plano, Wetzlar, Germany) followed by polymerization at $60^{\circ} \mathrm{C}$ for 24 hours. Semithin and 80-nm ultrathin sections were made with an ultramicrotome (Ultracut, Reichert-Jung, Vienna, Austria) and placed on grids. Ultrastructural analysis and photomicroscopy were performed with a transmission electron microscope (model EM 410, Philips, Eindhoven, the Netherlands).

Measurement of 6-TG levels in primary $\mathrm{CD}^{+} \mathrm{T}$ lymphocytes. Tlymphocytes were stimulated with antibodies to CD3 and to CD28 as described above and treated with the indicated amounts of azathioprine for 5 days. Cells were washed in PBS, and the pellet was lysed in $200 \mu \mathrm{l}$ of $\mathrm{dH}_{2} \mathrm{O}$ followed by addition of $200 \mu \mathrm{l}$ of $2 \mathrm{~N} \mathrm{H}_{2} \mathrm{SO}_{4}$. The samples were boiled at $95^{\circ} \mathrm{C}$ for 15 minutes to release 6-TG. Samples were analyzed for 6-TG content using high-performance liquid chromatography, as previously described (19).

Isolation of $m R N A$ from primary $T$ lymphocytes. T lymphocytes were stimulated with antibodies to $\mathrm{CD} 3$ and CD28 in the presence or absence of azathioprine or 6-MP. The mRNA of $\mathrm{T}$ cells was extracted at the indicated time points using the Tri-reagent (SigmaAldrich) according to the manufacturer's protocol. In brief, the cell pellet was lysed in $1 \mathrm{ml}$ of Tri-reagent before addition of $200 \mu \mathrm{l}$ of chloroform (SigmaAldrich, Steinheim, Germany). Each sample was gently mixed before incubation (for 5 minutes at $20^{\circ} \mathrm{C}$ ) and centrifugation $\left(12,000 \mathrm{~g}\right.$ for 15 minutes at $\left.4^{\circ} \mathrm{C}\right)$. The aqueous phase was transferred to a fresh tube, and 0.5 $\mathrm{ml}$ of isopropanol (Sigma-Aldrich) was added. Samples were allowed to stand for 5 minutes at room temperature before centrifugation at $12,000 \mathrm{~g}$ (for 10 minutes at $4^{\circ} \mathrm{C}$ ). The supernatants were removed, and the RNA pellet was washed in $75 \%$ ethanol.

Gene arrays. mRNA from $T$ lymphocytes was analyzed by the human apoptosis expression array (R\&D) as follows. To generate radiolabeled cDNA, $4 \mu \mathrm{l}$ of human apoptosis-specific primers (R\&D) were added to $4 \mu \mathrm{g}$ of the isolated mRNA, heated in a thermal cycler at $90^{\circ} \mathrm{C}$ for 2 minutes, and incubated at $42^{\circ} \mathrm{C}$ for 180 minutes in the presence of reverse transcriptase buffer $(50 \mathrm{mM}$ Tris- $\mathrm{HCl}, 8 \mathrm{mM} \mathrm{MgCl}, 30 \mathrm{mM} \mathrm{KCl}, 1 \mathrm{mM}$ DTT), $333 \mu \mathrm{M}$ dATP, $333 \mu \mathrm{M}$ dGTP, $333 \mu \mathrm{M}$ dTTP, 
$1.67 \mu \mathrm{M}$ dCTP, $20 \mathrm{U}$ of RNasin, $20 \mu \mathrm{Ci}$ of ${ }^{32} \mathrm{P}$-labeled dCTP (Amersham, Freiburg, Germany), and $50 \mathrm{U}$ of AMV reverse transcriptase. For hybridization, denatured salmon testis DNA (Sigma-Aldrich) was prewarmed to $65^{\circ} \mathrm{C}$ in hybridization solution $(0.9 \mathrm{M}$ $\mathrm{NaCl}, 0.05 \mathrm{M}$ sodium phosphate, $5 \mathrm{mM}$ EDTA, $2 \%$ SDS, $0.1 \%$ PVP, $0.1 \%$ BSA, $0.1 \%$ Ficoll). The cDNA expression array was prehybridized in $5 \mathrm{ml}$ of the prewarmed solution for 1 hour at $65^{\circ} \mathrm{C}$, followed by addition of the heat-denatured labeled cDNA. After overnight hybridization at $65^{\circ} \mathrm{C}$, the cDNA expression array was washed in wash solution $(90 \mathrm{mM} \mathrm{NaCl}, 5$ mM sodium phosphate, $0.5 \mathrm{mM}$ EDTA, $1 \%$ SDS), air dried, and subjected to autoradiography overnight at $80^{\circ} \mathrm{C}$ using Kodak BioMax MR films (Kodak, Rochester, New York, USA).

Preparation of cellular extracts. Cells were treated with azathioprine and 6-MP for the indicated periods of time before extraction of cellular proteins. The cells were then washed in PBS, resuspended in $1 \mathrm{ml}$ of $\mathrm{T}_{40} \mathrm{E}_{10} \mathrm{~N}_{150}$ buffer (40 mM Tris- $\mathrm{HCl}[\mathrm{pH} 7.9], 10 \mathrm{mM}$ EDTA [pH 8.0], $150 \mathrm{mM} \mathrm{NaCl}$ ), put on ice for $5 \mathrm{~min}$ utes, and centrifuged for 4 minutes at $4^{\circ} \mathrm{C}$ at 1,000 $\mathrm{rpm}$. The cell pellet was then resuspended on ice in 70 $\mu \mathrm{l}$ of buffer (10 mM HEPES [pH 8.0], $400 \mathrm{mM} \mathrm{NaCl}$, $0.1 \mathrm{mM}$ EDTA, 5\% glycerol, $1 \mathrm{mM}$ DTT, $1 \mathrm{mM}$ PMSF) and centrifuged at $15,000 \mathrm{rpm}$ for 30 minutes at $4^{\circ} \mathrm{C}$. The protein concentrations in supernatants were determined with the Bio-Rad Protein Assay (Bio-Rad, Munich, Germany).

Isolation of nuclear proteins. $\mathrm{T}$ lymphocytes were washed twice in cold PBS and resuspended in $500 \mu \mathrm{l}$ of buffer A (10 mM HEPES, $1.5 \mathrm{mM} \mathrm{MgCl}_{2}, 19 \mathrm{mM} \mathrm{KCl}$, $0.5 \mathrm{mM}$ PMSF, $1 \mathrm{mM}$ DTT) followed by addition of 20 $\mu \mathrm{l}$ of Triton X-100 (Sigma-Aldrich) and incubation on ice for 5 minutes. Cells were centrifuged for $10 \mathrm{~min}$ utes at $4{ }^{\circ} \mathrm{C}$, followed by the resuspension of the nuclear pellet in buffer C (20 mM HEPES, $1.5 \mathrm{mM}$ $\mathrm{MgCl}_{2}, 0.2 \mathrm{mM}$ EDTA, 25\% glycerol, $0.5 \mathrm{mM}$ PMSF, 1 $\mathrm{mM}$ DTT). Finally, the nuclei were homogenized using mini stir bars for 1 hour at $4^{\circ} \mathrm{C}$ followed by centrifugation at $15,000 \mathrm{rpm}$ for 15 minutes at $4^{\circ} \mathrm{C}$. The concentration of nuclear proteins in supernatants was assessed using the Bio-Rad Protein Assay.

Western blots. Equal amounts of extract $(30 \mu \mathrm{g})$ were added to $8 \mu$ l of electrophoresis sample buffer (Firma Roth, Karlsruhe, Germany). After boiling, the extracts were loaded on $15 \%$ SDS-PAGE gels and electrophoretically separated. Proteins were transferred to nitrocellulose membranes, and detection was performed with the ECL Western blotting analysis system (Amersham). Western blots were made using the following antibodies: anti-human bcl- $\mathrm{x}_{\mathrm{L}}$ antibody (1:1000 dilution; Oncogene, Cambridge, Massachusetts, USA), anti-human signal transducer and activator of transcription-3 (STAT-3), anti-human $\beta$-actin, anti-human ERK2 (Dianova, Hamburg, Germany), anti-human Rac1, anti-human vav, anti-human MEK, anti-human STAT3 (1:500 dilution, Santa Cruz Biotech), anti-phospho-IкB, anti-phospho-
MEK (1:1000 dilution, PharMingen and R\&D), and HRP-linked anti-mouse, anti-rabbit, or anti-goat Ig (1:5000 dilution; Amersham). Densitometry of Western blots was performed using the ChemiImager 5500 software (Alpha Innotech, San Leandro, California, USA).

Electrophoretic mobility shift assays. Electrophoretic mobility shift assays (EMSAs) were performed as previously described (30). Oligonucleotides for EMSA were obtained from Santa Cruz Biotech (Heidelberg, Germany). The sequences were as follows: NF-KB, $5^{\prime}$ AGTTGAGGGGACTTTCCCAGGC-3' and 3 '-TCAACTCCCCTGAAAGGGTCCG-5'; and SP-1, 5'-ATTCGATCGGGGCGGGGCGAGC-3' and $3^{\prime}$-TAAGCTAGCCCCGCCCCGCTCG- $5^{\prime}$. Oligonucleotides were end labeled with $\left[{ }^{32} \mathrm{P}\right] \gamma-$ ATP (>5000 Ci $/ \mathrm{mmol}$; Amersham, Arlington Heights, Illinois, USA) using T4 polynucleotide kinase (New England Biolabs, Beverly, Massachusetts, USA). Radiolabeled DNA $(25,000 \mathrm{cpm})$ were added to the binding reaction that also contained $1 \mu \mathrm{g}$ of synthetic DNA duplex of poly(dIdC) (Pharmacia, Piscataway, New Jersey, USA), $15 \mu \mathrm{g}$ of nuclear proteins, and binding buffer (25 mM HEPES [pH 7.5], $150 \mathrm{mM} \mathrm{KCl,} 5 \mathrm{mM}$ DTT, $10 \%$ glycerol). For supershift assays, $1 \mu \mathrm{g}$ of antibodies specific for the p50 or p65 subunit of NF-KB (both obtained from Santa Cruz Biotech) were used. Complex formation was allowed to proceed for 30 minutes at room temperature. Finally, the complexes were separated from unbound DNA by native polyacrylamide gel electrophoresis on $5 \%$ gels. The gels were exposed to Kodak MS films on intensifying screens at $-80^{\circ} \mathrm{C}$.

Analysis of proteolytic activity of caspase-3, caspase- 8 , and caspase-9. T lymphocytes were incubated with the indicated amounts of azathioprine or 6-MP as specified in the Results. Caspase- 3 proteolytic activity was determined at day 5 by the caspase-3/CPP 32 fluorometric protease assay (Bio Source, Worcester, Massachusetts, USA) according to the manufacturer's protocol. Caspase-8 and caspase-9 proteolytic activity were assessed in parallel by the corresponding fluorometric protease assays (Bio Source).

Measurement of the mitochondrial membrane potential. Changes in the mitochondrial membrane potential $\left(\Delta \Psi_{\mathrm{m}}\right)$ were estimated in primary $\mathrm{CD} 4^{+} \mathrm{T}$ lymphocytes loaded with the $\Delta \Psi_{\mathrm{m}}$-sensitive fluorescent dye JC-1 (Molecular Probes, Eugene, Oregon, USA). Cells were loaded with JC-1 $(10 \mu \mathrm{g} / \mathrm{ml})$ for 20 minutes at $37^{\circ} \mathrm{C}$, rinsed with dye-free PBS, and analyzed by FACS. The fluorescence emission wavelength of JC-1 depends on the aggregation of the JC- 1 molecules that in turn depend on the $\Delta \Psi_{\mathrm{m}}$ (the greater the $\Delta \Psi_{\mathrm{m}}$, the greater the aggregation). Changes in $\Delta \Psi_{\mathrm{m}}$ were measured by monitoring JC-1 fluorescence at $590 \mathrm{~nm}$. Carbonylcyanide-4-(trifluoromethoxy)-phenylhydrazone (FCCP; Biomol, Plymouth Meeting, Pennsylvania, USA), a substance that induces depolarization of the mitochondrial membrane potential, was used as a positive control. Cells were treated with FCCP $(50 \mu \mathrm{M})$ for 18 hours.

Blocking of caspase-8 and caspase-9 activity. Primary $\mathrm{CD}^{+} \mathrm{T}$ lymphocytes from peripheral blood were iso- 
lated as described above and stimulated with antibodies to CD3 and CD28 in the presence or absence of indicated amounts of $\mathrm{N}$-acetyl-Leu-Glu-His-Asp-aldehyde (Biomol), a reversible inhibitor of caspase- 9 , or Ac-Ile-Glu-Thr-Asp-aldehyde (Bachem, Heidelberg, Germany), an inhibitor of caspase-8. Apoptosis was determined by FACS analysis after 5 days of cell culture.

Rac and Ras activation assays. We determined the levels of Rac1- and Ras-bound GTP by immunoblot techniques (Upstate Biotech, London, United Kindom). In brief, $T$ cells were stimulated for indicated periods of time in the presence or absence of azathioprine, 6-MP, or 6-TG. Cell lysates were incubated with $10 \mu \mathrm{g} / \mathrm{ml}$ PAK-1 agarose (Rac assays) or $10 \mu \mathrm{g} / \mathrm{mg}$ Raf RBD agarose (Ras assay) for 60 minutes (Rac assays) or 30 minutes (Ras assays) at $4^{\circ} \mathrm{C}$. Agarose beads were collected by centrifugation followed by denaturation, boiling of the samples, and SDS-PAGE analysis. Proteins were transferred to nitrocellulose membranes and incubated with $1 \mu \mathrm{g} / \mathrm{ml}$ murine anti-human Rac1 or anti-human
Ras (clone Ras10) antibodies overnight at $4^{\circ} \mathrm{C}$, followed by detection with goat anti-mouse HRP-conjugated IgG (1:1000 dilution) and the ECL detection system. To analyze the capacity of 6-Thio-GTP to bind to Rac1 or Ras, chemically synthesized 6-Thio-GTP (obtained from Jena Bioscience, Jena, Germany) was used. Recombinant Rac1 or Ras was incubated with radiolabeled GTP $\left(\left[{ }^{3} \mathrm{H}\right] \mathrm{GTP}\right.$, Amersham) and increasing amounts of 6-Thio-GTP $(0-500 \mu \mathrm{M})$ followed by Rac1 and Ras pull-down through PAK and Raf RGD and analysis of $\left[{ }^{3} \mathrm{H}\right] \mathrm{GTP}-$ bound Rac1 or Ras by scintillation counting.

Immunocytochemical analysis. Immunocytochemistry was performed as described previously $(30,43)$. Briefly, $\mathrm{T}$ cells were stimulated as above with IL-2 and antibodies to CD3 and CD28 and cultured in Lab-Tec chambered coverglass (Nunc, Wiesbaden, Germany) for 3-5 days, as specified in the Results. The cells were then fixed in 4\% paraformaldehyde/ PBS for 15 minutes and washed twice in $0.01 \mathrm{M}$ PBS $/ 0.1 \%$ Tween. Cells were then pretreated with 3\% BSA in PBS/0.1\% Tween
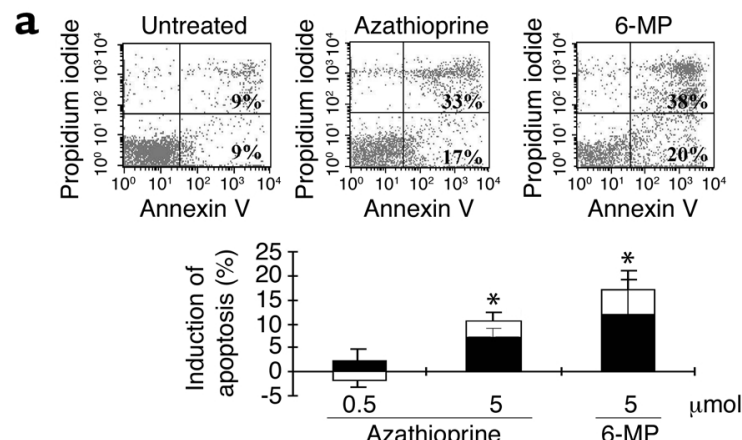

b
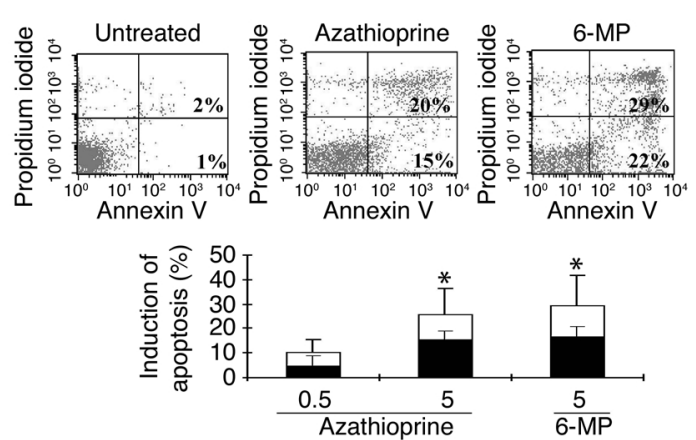

C
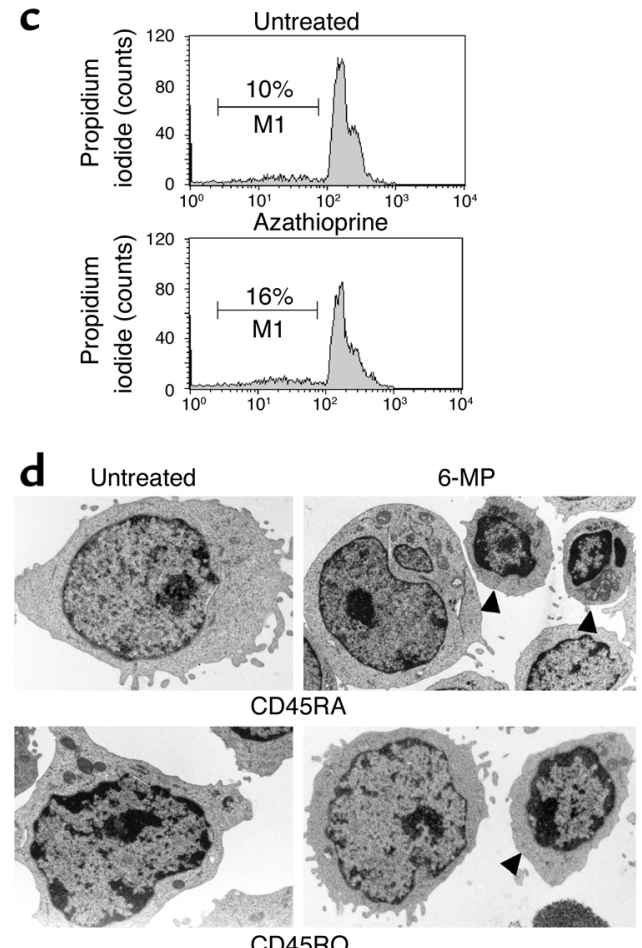

CD45RO

\section{Figure 1}

Azathioprine and its metabolites induce T cell apoptosis. CD45RA (a) and CD45RO (b) T cell subsets were isolated from peripheral blood of healthy volunteers and stimulated with antibodies to CD3 and CD28 and recombinant IL-2 in the presence or absence of indicated concentrations of azathioprine and 6-MP. T cell apoptosis was assessed by FACS analysis after 5 days of cell culture. Azathioprine and 6-MP led to an induction of annexin-positive, propidium iodide-negative T cells, suggesting that they induced T cell apoptosis. The FACS data is representative of 6-10 independent experiments per group. The average induction of specific apoptosis from 6-10 patients per group (induction of annexinpositive, propidium iodide-negative cells compared with untreated cells indicated by black sections of bars, induction of annexin-positive, propidium iodide-positive cells compared with untreated cells indicated by white sections) by azathioprine and 6-MP \pm SEM is shown in the lower panels. Statistically significant changes are indicated $\left({ }^{*} P<0.01\right)$. (c) Determination of apoptosis and cell cycle distribution by the Nicoletti technique. Peripheral blood $\mathrm{CD} 4^{+} \mathrm{T}$ cells from healthy volunteers were stimulated as above for 5 days, followed by analysis of DNA content by the Nicoletti technique. The percentage of apoptotic cells in the subdiploid peak is indicated by M1. (d) Azathioprine and 6-MP induce morphologic changes of CD45RA CD4 ${ }^{+} \mathrm{T}$ cells (upper panels) and CD45RO CD4 ${ }^{+} \mathrm{T}$ cells (lower panels) indicative of apoptosis, as assessed by transmission electron microscopy. Peripheral blood $\mathrm{CD} 4^{+} \mathrm{T}$ cells from healthy volunteers were stimulated as above for 5 days. Upon 6-MP treatment, T cells exhibited typical signs of apoptosis (arrowheads), with dense nuclear condensation and degeneration of organelles. Magnification, $\times 7200$. 


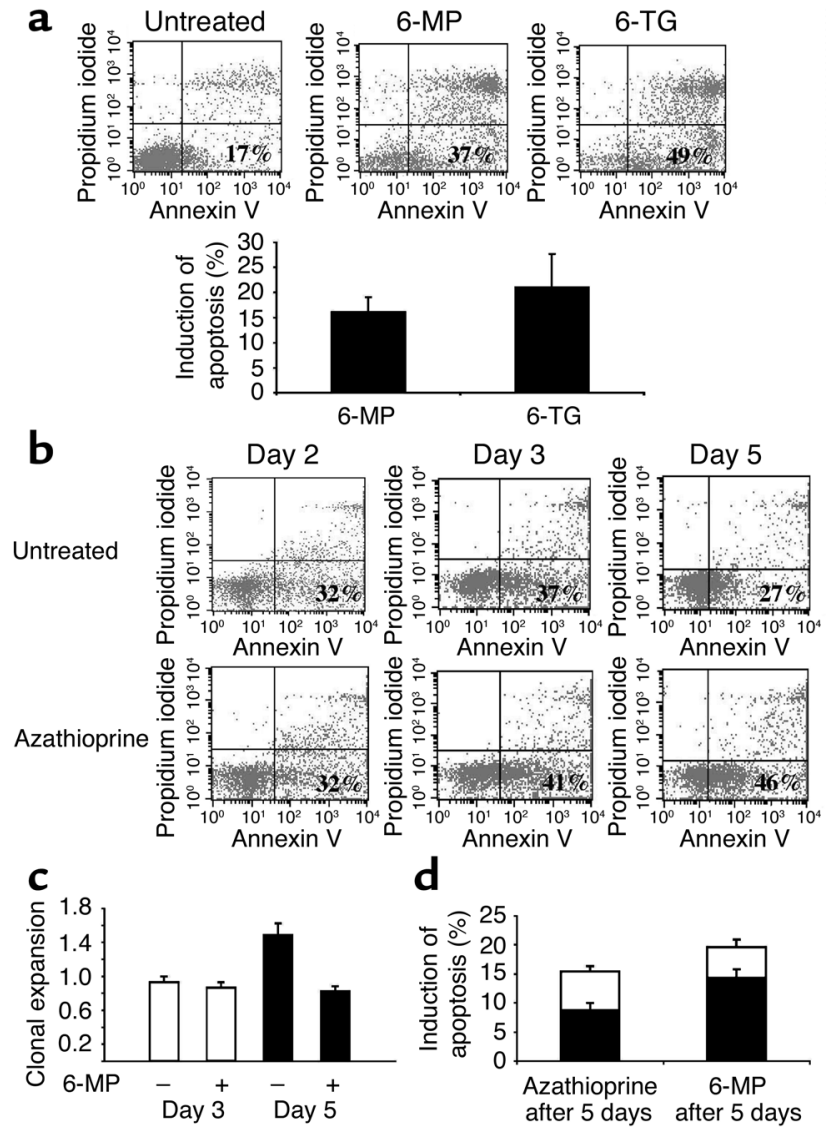

for 30 minutes at room temperature and incubated for 1 hour at room temperature with the primary antibody (1:200 dilution of rabbit anti-human Rac1 or rabbit anti-human vav; Santa Cruz Biotech, Hercules, California, USA, or PharMingen) in PBS/0.1\% Tween. Samples without primary antibody or isotope control antibodies served as negative control and resulted in no staining (data not shown). Next, samples were rinsed in PBS and incubated with Cy3-labeled goat anti-rabbit IgG antibodies (1:200 dilution; Jackson Immuno Research, Hamburg, Germany) for 1 hour at room temperature. Cells were rinsed with PBS, and nuclei were counterstained with Hoechst 33342 blue for fluorescence (Molecular Probes, Burlingame, California, USA). Finally, cells were washed in PBS and analyzed with an Olympus Microscope. Six to ten high-power fields were finally analyzed in all patients per condition, and selected high-power fields were further analyzed by confocal laser microscopy.

Statistical analysis. Tests for significance of differences were made by Student's $t$ test using the program StatWorks (Macintosh, Wiesbaden, Germany).

\section{Results}

Azatbioprine and its metabolites induce apoptosis of activated and preactivated $\mathrm{CD}^{+}$T cells from peripheral blood. Azathioprine and its metabolite 6-MP are immunosuppressive drugs that are frequently used for treatment of autoimmune and chronic inflammatory diseases

\section{Figure 2}

(a) Peripheral blood $\mathrm{CD} 4^{+} \mathrm{T}$ cells from healthy volunteers were stimulated with antibodies to CD3 and CD28 and recombinant IL-2 and cultured in the presence or absence of 6-MP and 6-TG for 4-5 days. T cell apoptosis was assessed by FACS analysis (upper panels). The average level of 6-MP- and 6-TG-specific apoptosis (induction of annexin-positive, propidium iodide-negative T cells compared with untreated cells) \pm SEM from four independent experiments is shown in the lower panel. (b) Kinetics of azathioprine-induced apoptosis in primary CD4 $4^{+} \mathrm{Tlym}$ phocytes. $\mathrm{CD} 4^{+} \mathrm{T}$ cells were cultured in the presence or absence of azathioprine for 2-5 days as indicated. T cell apoptosis was assessed by FACS analysis at the indicated time points. (c) 6-MP suppresses clonal expansion of activated primary $\mathrm{CD} 4^{+} \mathrm{T}$ lymphocytes in cell culture. $\mathrm{CD}^{+} \mathrm{T}$ cells were cultured in the presence $(+)$ or absence (-) of 6-MP for 3-5 days. The clonal expansion of T cells during cell culture was calculated as specified in Methods. (d) $\mathrm{CD} 4{ }^{+} \mathrm{T}$ cells were cultured in the absence of azathioprine or 6-MP for 5 days, followed by addition of azathioprine or 6-MP to the cell culture for an additional 5 days. The percentage of annexin-positive, propidium iodide-negative cells was then determined at day 10 by FACS analysis. The average percentage of azathioprine- and 6-MP-specific apoptosis (induction of annexinpositive, propidium iodide-negative cells compared with untreated cells indicated by black sections of bars, induction of annexin-positive, propidium iodide-positive cells compared with untreated cells indicated by white sections) \pm SEM is shown in the lower panel.

such as Crohn disease $(11,34)$. Since the regulation of $T$ cell apoptosis plays a major role in these diseases (44, 45), we wanted to determine whether azathioprine induces apoptosis of primary naive or memory $\mathrm{CD}^{+}$ T lymphocytes upon activation through the TCR/CD3 complex and CD28. Accordingly, peripheral blood CD45RA and CD45RO $\mathrm{CD}^{+}{ }^{+} \mathrm{T}$ cell subsets from healthy volunteers were isolated and stimulated with recombinant IL-2 and anti-CD3 plus anti-CD28 antibodies in the presence or absence of azathioprine and 6-MP. As shown in Figure 1a, we found that both azathioprine and 6-MP caused a significant induction of annexin $\mathrm{V}$-positive, propidium iodide-negative naive CD45RA T cells after 5 days, suggesting that these drugs are able to induce $T$ cell apoptosis. Similar to CD45RA T cells, azathioprine and 6-MP induced apoptosis of CD45RO memory T cells (Figure $1 \mathrm{~b}$ ), and this effect on average was even more pronounced than in CD45RA T cells. Azathioprine and 6-MP also induced a marked increase in the number of apoptotic $\mathrm{CD} 4^{+} \mathrm{T}$ cells, as assessed by Nicoletti staining and transmission electron microscopy (Figure 1, $c$ and d). $\mathrm{T}$ cell apoptosis occurred at low concentrations (5 $\mu \mathrm{M}$ ) of azathioprine (Figure 1, a and b). This concentration of azathioprine resulted in intracellular 6-TG levels at day $5(31.5 \mathrm{pmol} / \mathrm{mg}$ DNA at $0.5 \mu \mathrm{M}$ azathioprine and $168 \mathrm{pmol} / \mathrm{mg}$ DNA at $5 \mu \mathrm{M}$ azathioprine versus $0 \mathrm{pmol} / \mathrm{mg}$ DNA at $0 \mu \mathrm{M}$ azathioprine) that were comparable to those reported in leukocytes of patients with Crohn disease receiving long-term azathioprine or 6-MP treatment (100-2,305 pmol/mg DNA) (46), suggesting that this concentration is relevant for therapy with azathioprine in vivo. Since 6-TG is a key metabolite with immune modifier activity of both azathioprine 
a

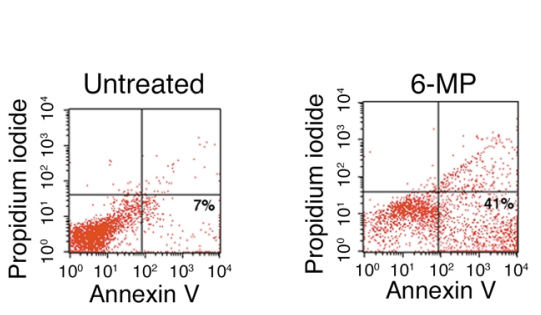

b

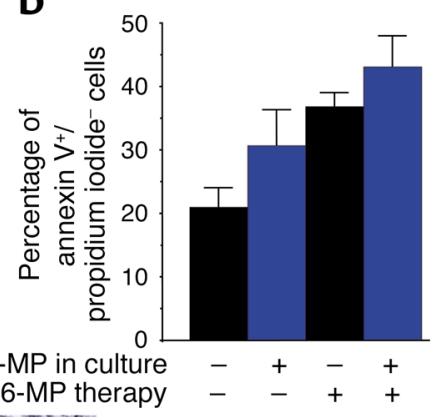

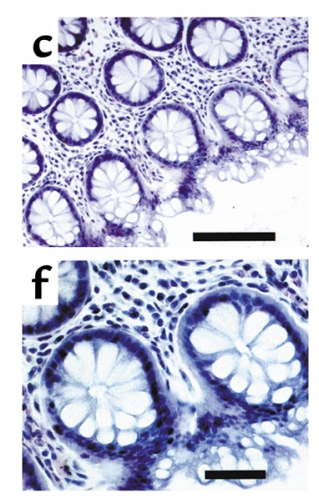
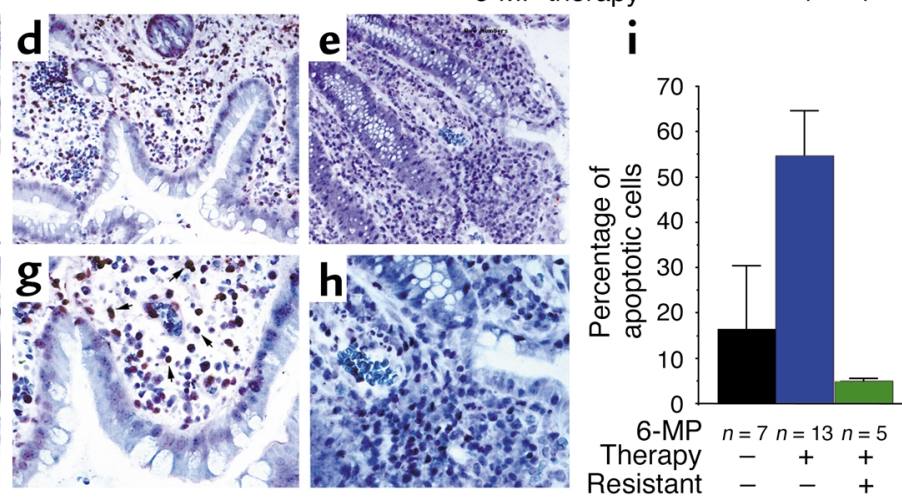

Figure 3

Azathioprine treatment induces T cell apoptosis in IBD. (a) LPMCs were isolated and stimulated with anti-CD2/CD28 plus IL-2 in the presence or absence of 6-MP for 5 days followed by FACS analysis. (b) Peripheral blood CD4 ${ }^{+} T$ cells were isolated from patients with IBD receiving azathioprine/6-MP and patients with IBD before therapy and stimulated with anti-CD3/CD28 plus IL-2 in the presence or absence of 6-MP for 5 days. The number of apoptotic cells (annexin-positive, propidium iodide-negative cells) was determined by FACS analysis after 5 days and stratified according to clinical data on azathioprine therapy. Data represent mean values \pm SEM from eight patients with IBD per group. (c-h) TUNEL assays for the detection of apoptotic lamina propria cells in patients with IBD under azathioprine therapy. Successful azathioprine treatment associated with low-level gut inflammation was characterized by a high number of apoptotic cells (shown at low [d] and high [g] magnification) as compared with control patients with low-level gut inflammation not receiving azathioprine (c and $\mathbf{f}$ ). In contrast, unsuccessful azathioprine treatment associated with high-level gut inflammation was characterized by a very low percentage of apoptotic cells $(\mathbf{e}$ and $\mathbf{h})$. Data are representative of 5-13 patients per group. Magnification, $\times 20($ bar $=100 \mu \mathrm{m})(\mathbf{c}-\mathbf{e})$ and $\times 40($ bar $=50 \mu \mathrm{m})$ $(\mathbf{f}-\mathbf{h})$. (i) Quantification of the percentage of apoptotic, TUNEL-positive LPMCs in patients with IBD receiving 6-MP as compared with untreated control patients. Clinical 6-MP responsiveness was associated with a marked, significant $(P<0.01)$ increase in the percentage of apoptotic LPMCs as compared with control patients with IBD not receiving 6-MP. Data are mean values \pm SEM of 5-13 patients per group.

and 6-MP (14), these data were also consistent with the hypothesis that therapeutically relevant 6-TG concentrations directly induced apoptosis in azathioprinetreated primary $\mathrm{T}$ cells. In subsequent studies, we therefore tested whether 6-TG was able to induce apoptosis. As shown in Figure 2a, 6-TG induced a marked apoptosis of primary blood $\mathrm{CD}^{+} \mathrm{T}$ lymphocytes that was at least comparable to the effects of 6-MP, consistent with the idea that 6-TG mediates the immunosuppressive properties of azathioprine and 6-MP.

Kinetic studies showed that azathioprine and 6-MP induced $T$ cell apoptosis after 4-5 days of cell culture only (Figure 2b), whereas no apoptosis induction was noted during the first 2 days after administration. This data is consistent with the well-known delayed onset of clinical activity of this drug (14). Azathioprine-induced induction of apoptosis was accompanied by a reduction in the clonal expansion of $\mathrm{T}$ cells at day 5 , whereas no significant changes were seen at earlier time points (Figure 2c).

The above data suggested that azathioprine and its metabolites induce apoptosis of $\mathrm{T}$ lymphocytes upon stimulation with recombinant IL-2 (rIL-2) and antibodies to CD3 plus CD28. To clarify whether azathioprine can also induce apoptosis of already preactivated $\mathrm{T}$ lymphocytes, we performed experiments in which azathioprine or 6-MP was added after 5 days to the T cell culture. Accordingly, azathioprine or 6-MP was added at day 5 to the $T$ cell cultures, and apoptosis was determined by annexin $\mathrm{V}$ /propidium iodide staining at day 10. Interestingly, azathioprine also induced apoptosis when added at this time point, suggesting that this drug is capable of inducing apoptosis in already preactivated T lymphocytes (Figure 2d).

Azathioprine treatment induces apoptosis of blood and lamina propria $T$ cells in patients with inflammatory bowel diseases. Next, we wanted to determine whether azathioprine is capable of inducing $\mathrm{T}$ cell apoptosis in autoimmune or chronic inflammatory diseases in vivo. In these studies, we focused on patients with IBDs such as ulcerative colitis and Crohn disease, for whom azathioprine is considered the gold standard of immunosuppressive therapy $(11,21)$. It was found that 
a
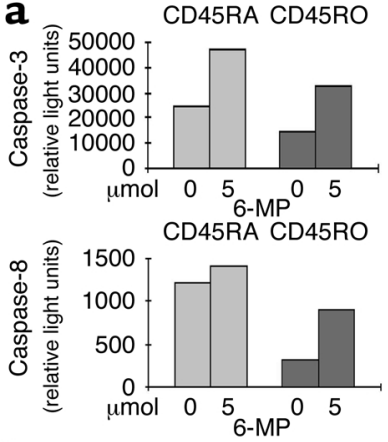

b

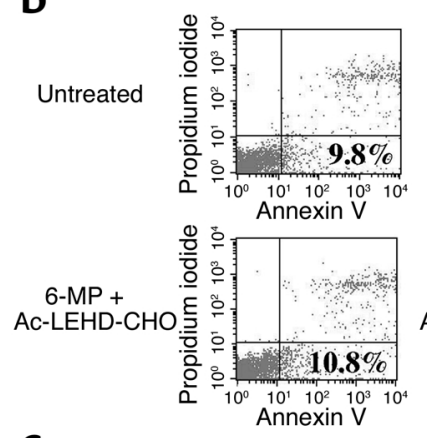

C
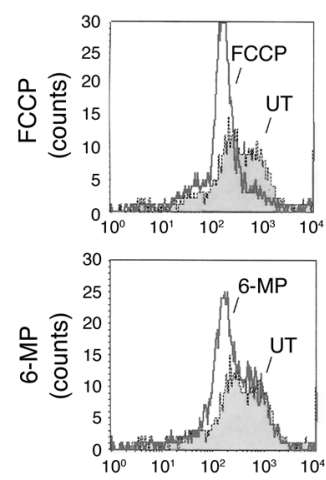
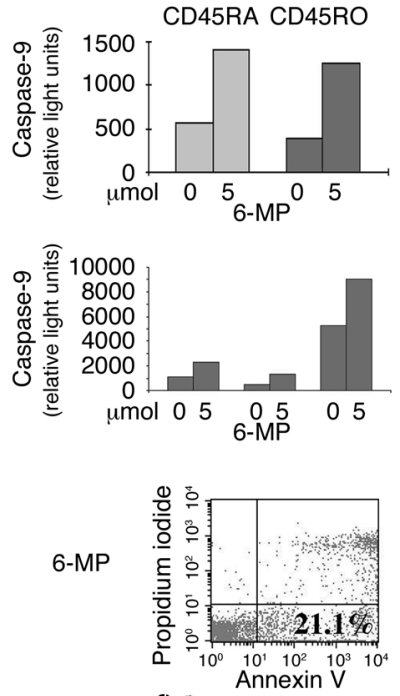

$6-\mathrm{MP}+$
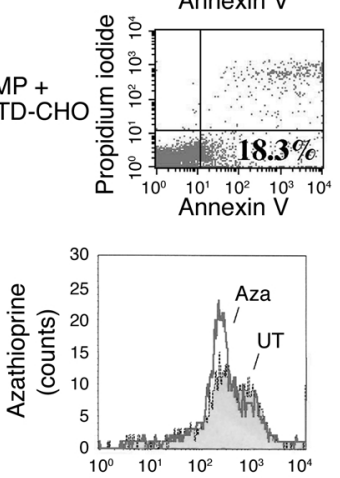

patients treated with azathioprine or 6-MP showed a significant increase $(P<0.05)$ in the number of apoptotic blood $\mathrm{T}$ cells when the cells were stimulated with CD28 in cell culture as compared with untreated patients before therapy (Figure $3 b$ ). An additional treatment of $\mathrm{T}$ cells from 6-MP-treated patients with 6-MP in vitro did not cause a further significant increase in the percentage of apoptotic cells, suggesting that the patients were treated with sufficient dosages of 6-MP in vivo. Furthermore, we observed that 6-MP is capable of inducing apoptosis in antiCD2 plus anti-CD28 activated lamina propria lymphocytes in ulcerative colitis (Figure 3a), suggesting that the beneficial effect of this drug in IBD could be due to the induction of local $\mathrm{T}$ cell apoptosis in areas of intestinal inflammation. Consistent with this hypothesis, we found that successful 6-MP treatment in patients with IBD led to a significant increase $(P<0.01)$ in the number of apoptotic lamina propria mononuclear cells as compared with untreated patients with IBD (Figure 3, c-i). In contrast, 6-MPresistant patients with IBD showed no increase in the

\section{Figure 4}

Azathioprine induces a mitochondrial pathway of apoptosis. (a) Activity of caspase- $3,-8$, and -9 upon treatment of T cells with 6-MP. CD45RA and CD45RO T cell subsets were stimulated with antibodies to CD3 and CD28 and recombinant IL-2 for 5 days in the presence or absence of 6-MP, as indicated. There was a marked induction of caspase- 9 activity upon azathioprine treatment. A second independent experiment showed similar results (data not shown). Data on caspase- 9 activity from three independent healthy blood donors are shown in the right lower panel. (b) Specific blockade of caspase-9 by acetyl-LEHD-CHO (Ac-LEHD-CHO) suppresses 6-MP-induced apoptosis. $\mathrm{CD} 4^{+} \mathrm{T}$ lymphocytes from the peripheral blood of healthy volunteers were stimulated with antibodies to CD3 and CD28 in the presence or absence of 6-MP, $10 \mu \mathrm{M}$ acetyl-LEHD-CHO, and $10 \mu \mathrm{m}$ acetyl-IETD-CHO. Although acetyl-IETD-CHO had little effect, 6-MPinduced $\mathrm{T}$ cell apoptosis could be suppressed by acetyl-LEHD-CHO. (c) Measurement of $\Delta \Psi_{\mathrm{m}}$ in primary $C D 4^{+} T$ lymphocytes upon treatment with azathioprine, 6-MP, and FCCP (positive control). Peripheral blood $\mathrm{CD}^{+} \mathrm{T}$ cells from healthy volunteers were stimulated with antibodies to CD3 and CD28 and recombinant IL-2 and cultured in the presence or absence of azathioprine or 6-MP for 5 days as indicated. Cells were then loaded with JC- 1 for 20 minutes followed by FACS analysis to determine $\Delta \Psi_{\mathrm{m}}$. Both azathioprine and 6-MP as well as FCCP led to a marked reduction of $\Delta \Psi_{\mathrm{m}}$ as compared with untreated primary $\mathrm{CD}^{+} \mathrm{T}$ cells. One representative experiment of two is shown. Aza, azathioprine; UT, untreated.

number of apoptotic cells, suggesting that 6-MP responsiveness in patients with IBD correlates with the presence of apoptotic lamina propria cells.

Azathioprine and its metabolites induce a mitochondrial pathway of apoptosis that is related to CD28 signaling. In initial functional studies focusing on the mechanism of azathioprine-induced apoptosis, we next assessed activation of caspases in primary blood $\mathrm{T}$ lymphocytes by 6-MP. Accordingly, CD4+ $\mathrm{T}$ lymphocytes were stimulated with rIL-2 and anti-CD3 plus anti-CD28 antibodies in the presence or absence of 6-MP, and caspase activity was determined after 5 days. As shown in Figure 4a, 6-MP led to a marked induction of both caspase- 9 and caspase- 3 , whereas the induction of caspase- 8 , on average, was less pronounced. Since these data suggested that 6-MP-induced apoptosis might involve activation of a mitochondrial pathway of apoptosis involving caspase-9, we focused in consecutive studies on the role of caspase-9 in 6-MP-induced apoptosis. It was found that acetyl-LEHD-CHO, a substance that (at the concentrations used) specifically blocks caspase-9 activation (Figure 4b), suppressed 6-MP-induced apoptosis of primary $\mathrm{T}$ lymphocytes, whereas acetyl-IETD-CHO, a specific inhibitor of caspase-8, had lesser effects. These results strongly suggest that 6-MP utilizes a caspase-9-sensitive mitochondrial pathway to induce $\mathrm{T}$ cell apoptosis upon CD28 costimulation. Consistent with this hypothesis, both azathioprine and 6-MP led to a loss of $\Delta \Psi_{\mathrm{m}}$ in primary $T$ cells (Figure $4 c$ ) that is known to occur during mitochondrial pathways of apoptosis (47).

In subsequent studies on the mechanism of azathioprine-induced apoptosis, we determined the requirement of $\mathrm{T}$ cell costimulation with $\mathrm{CD} 28$ for 


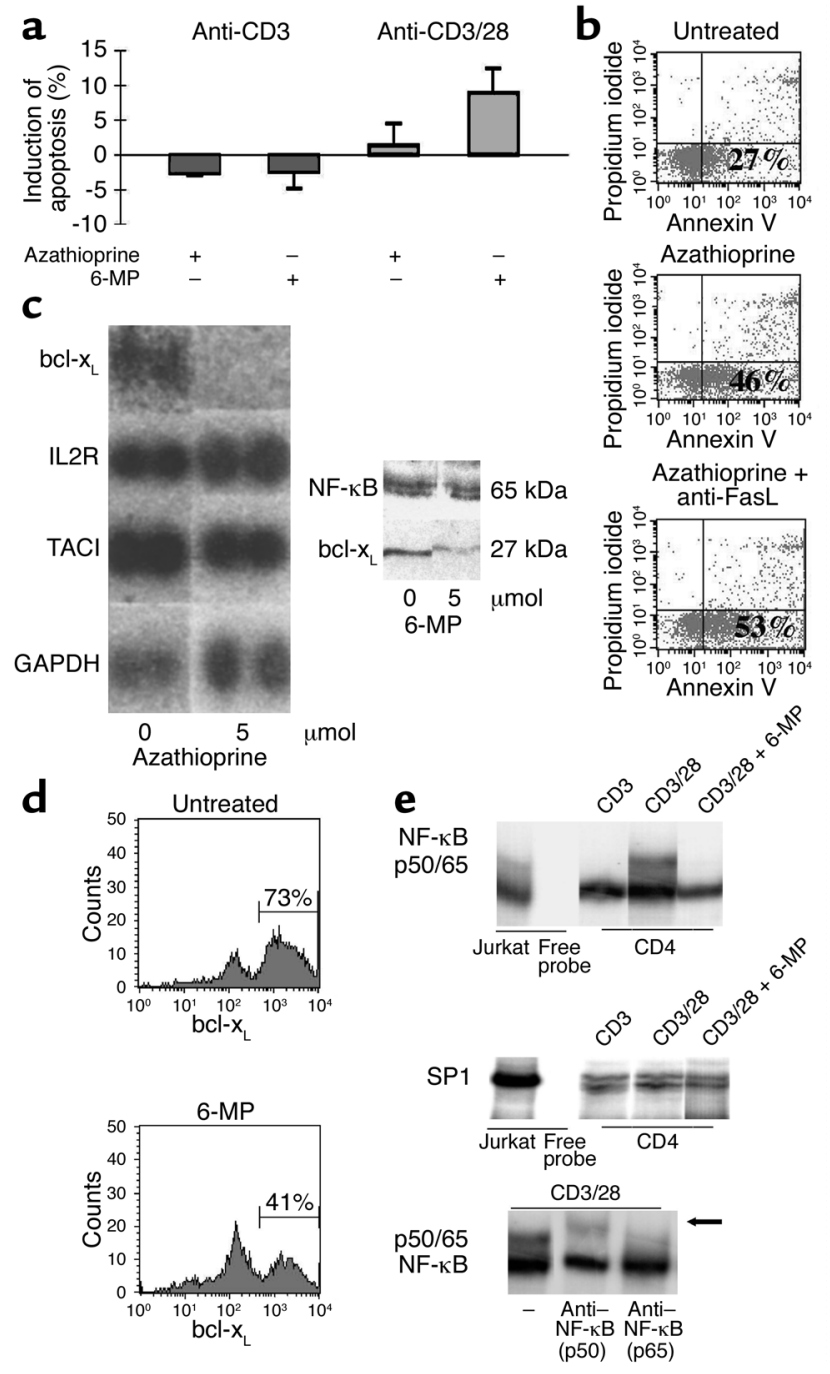

azathioprine- and 6-MP-induced apoptosis (Figure 5a). It was found that azathioprine and 6-MP induced apoptosis when primary blood $\mathrm{CD} 4^{+} \mathrm{T}$ lymphocytes were stimulated through the TCR/CD3 complex plus $\mathrm{CD} 28$, whereas no apoptosis was seen when cells were stimulated with anti-CD3 antibodies alone (Figure $5 a)$, demonstrating a selectivity of this drug for costimulated $\mathrm{T}$ lymphocytes. This requirement for CD28 costimulation led us to further investigate the CD28-related signaling events involved in azathioprine- and 6-MP-induced apoptosis.

CD28 costimulation has been shown to affect both the death receptor and the mitochondrial pathways of apoptosis induction (48). Given its implication in activation-induced cell death of T cells, we first studied the possible contribution of the CD95L/CD95 interaction to the apoptotic effect of azathioprine. Interestingly, we found that specific blockade of the CD95L/CD95 system by CD95L-neutralizing antibodies did not affect azathioprine-induced apoptosis of anti-CD3- plus antiCD28-stimulated primary blood $\mathrm{CD}^{+}{ }^{+} \mathrm{T}$ lymphocytes (Figure $5 \mathrm{~b}$ ), suggesting that azathioprine induces $\mathrm{T}$ cell apoptosis through a CD95-independent pathway.

\section{Figure 5}

(a) Azathioprine-induced apoptosis is critically dependent on costimulation with CD28. CD4+ Tlymphocytes were stimulated in the presence or absence of azathioprine and 6-MP, as indicated. T cell apoptosis was assessed by FACS analysis using annexin V/propidium iodide staining at day 5 of cell culture. (b) Azathioprine-induced apoptosis is independent of the CD95/CD95L system. Primary CD4+ T lymphocytes were stimulated as above in the presence or absence of azathioprine and a neutralizing CD95L antibody. T cell apoptosis was assessed by FACS analysis at day 5 of cell culture. (c) The left panel shows a gene array for apoptosis-related genes in T lymphocytes. $\mathrm{CD}^{+} \mathrm{T}$ lymphocytes were stimulated as above in the presence or absence of azathioprine. The right panel shows that 6-MP suppresses $b c l-x_{\llcorner}$protein expression. Cellular proteins were isolated after 3 days of cell culture and assessed for bcl- $x_{L}$ or cellular NF-KB expression by Western blot analysis. (d) FACS analysis for intracellular bcl- $x_{\llcorner}$expression in permeabilized lymphocytes upon 6-MP treatment. Purified $\mathrm{CD} 4^{+} \mathrm{T}$ lymphocytes were stimulated in the presence or absence of 6-MP. FACS analysis for bcl- $x_{L}$ in permeabilized cells was performed after 5 days of cell culture. (e) 6-MP suppresses nuclear NF-KB activation. $\mathrm{CD}^{+} \mathrm{T}$ lymphocytes were stimulated in the presence or absence of 6-MP, as indicated. Nuclear proteins were isolated after 3 days and analyzed for NF-KB (upper panel) or SP-1 (middle panel) activity by gel retardation assays (EMSAs). Nuclear extracts from PMA-stimulated Jurkat $T$ cells served as positive controls. The lower panel represents a supershift analysis of the upper complex using extracts from anti-CD3plus anti-CD28-stimulated primary $T$ cells. The addition of antibodies to p50 or p65 to the EMSA reaction is indicated. 6-MP treatment

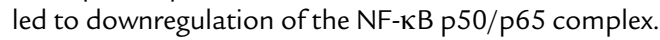

To identify candidate genes that may be responsible for azathioprine-induced apoptosis, we next characterized the gene products that are induced or suppressed by azathioprine during $\mathrm{T}$ cell apoptosis. In these studies, we used gene arrays that included various genes involved in apoptosis (Figure 5c). It was found that azathioprine strongly suppressed $\mathrm{bcl}-\mathrm{x}_{\mathrm{L}}$ mRNA expression in anti-CD3- plus anti-CD28-activated $\mathrm{T}$ lymphocytes, whereas mRNA expression of various other genes such as IL-2R, TACI, and GAPDH was not affected. Furthermore, bcl- $x_{\mathrm{L}}$ protein expression in activated $\mathrm{T}$ cells was strongly suppressed by azathioprine and 6-MP (Figure 5, c and d), strongly suggesting that azathioprine induces suppression of $\mathrm{bcl}-\mathrm{x}_{\mathrm{L}}$ mRNA and protein levels in activated primary $\mathrm{CD}^{+} \mathrm{T}$ lymphocytes. Since bcl- $\mathrm{x}_{\mathrm{L}}$ expression in $\mathrm{T}$ lymphocytes is known to be controlled by the transcription factor NF- $\mathrm{KB}(38,40,49)$, we next determined whether CD28-induced activation of NF- $\mathrm{KB}$ was altered in primary $\mathrm{T}$ lymphocytes upon 6-MP treatment. As shown in Figure 5e, 6-MP suppressed CD28induced activation of NF- $\mathrm{\kappa B} \mathrm{p} 50 / \mathrm{p} 65$. In particular, 6-MP downregulated the nuclear expression of the p65 subunit of NF- $\mathrm{KB}$ that has been implicated in antagonizing $\mathrm{T}$ cell apoptosis.

Azatbioprine causes a specific blockade of the Rac1 activation pathway in primary T lymphocytes. Since activation of NF-KB upon CD28 costimulation is mediated by phosphorylation and degradation of IкB (49), we next determined IкB phosphorylation in 6-MP-treated cells. It was found that IкB phosphorylation was sup- 
a
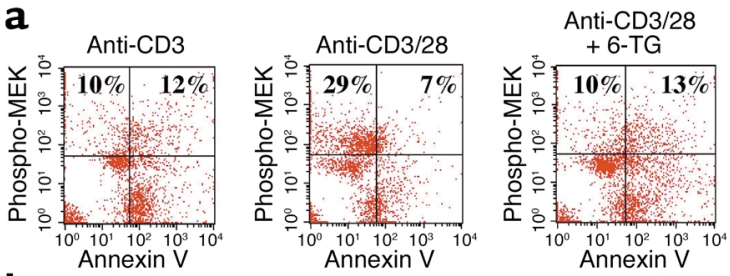

b

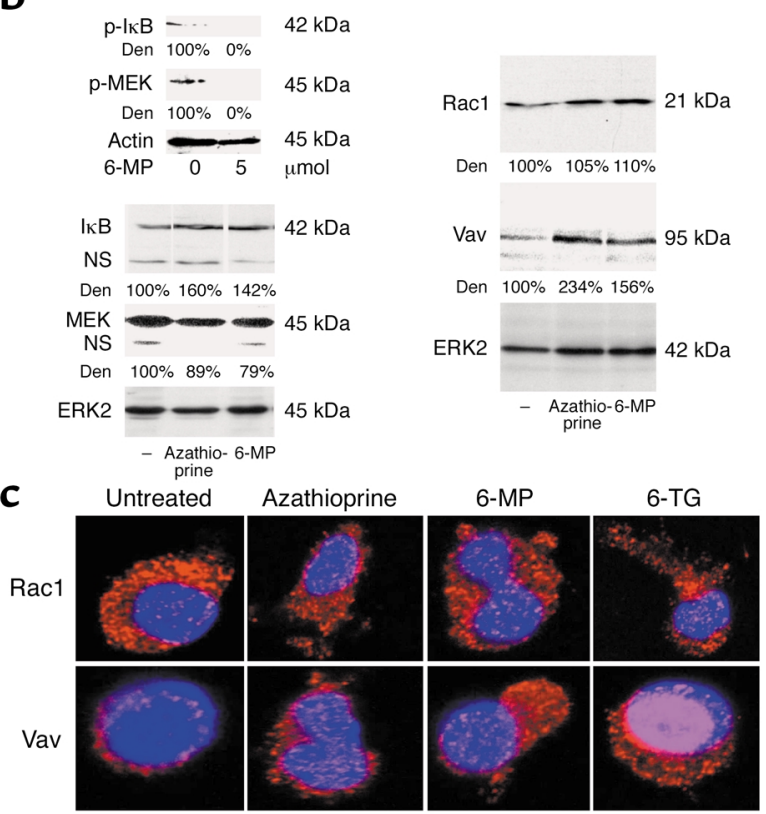

pressed by 6-MP treatment of $\mathrm{T}$ cells, whereas IкB protein expression levels remained unchanged (Figure $6 \mathrm{~b})$, strongly suggesting that CD28-mediated NF-KB activation through phosphorylation and degradation of IкB is a target of this drug. Since IкB phosphorylation in CD28-stimulated primary $\mathrm{T}$ cells is mediated by the vav/Rac1/MEK kinase (MEKK) activation pathway (49), we next assessed potential modulation of this pathway by azathioprine and 6-MP. Interestingly, we observed that azathioprine and its metabolites suppressed MEK phosphorylation, but the expression levels of MEK were nearly unchanged (Figure 6, a and b). Furthermore, the expression of Rac1 was not significantly suppressed by azathioprine and 6-MP, whereas both drugs induced the expression of the Rac1-activating guanosine exchange factor vav (Figure $6, \mathrm{~b}$ and $\mathrm{c}$ ), a regulatory protein previously shown to be a key target for CD28 signaling (50-52).

CD28 costimulation induced Rac1 activation in primary $\mathrm{T}$ cells (Figure 7a) was strongly suppressed by azathioprine, 6-MP, or 6-TG treatment, as shown by a reduction of GTP-bound Rac1 (Figure 7b). Since Rac1 is known to bind and activate STAT-3 (53), a key factor for regulating bcl- $x_{\mathrm{L}}$ expression in T cells (30), we also assessed Rac1-bound STAT- 3 and observed that Rac-1 bound STAT- 3 was reduced in azathioprinetreated $\mathrm{T}$ cells (Figure 7d). Rac1 activation upon CD28 costimulation thus appears to control both the NF- $\kappa \mathrm{B}$ and STAT-3 activation pathways that are

\section{Figure 6}

Azathioprine blocks the Rac1/MEK kinase pathway. (a) Analysis of phosphorylation of MEK, a MAP kinase kinase that can be activated by MEKK (see Figure 8 ). Purified $\mathrm{CD}^{+} \mathrm{T}$ lymphocytes were stimulated in the presence or absence of 6-TG. Intracellular staining for phospho-MEK by FACS analysis was made after 3 days. (b) 6-MP suppresses CD28-induced MEK and IKB phosphorylation. Purified $\mathrm{CD}^{+} \mathrm{T}$ lymphocytes were stimulated in the presence or absence of 6-MP. Cellular proteins were isolated after 3 days and analyzed by Western blotting. The upper left panels show phospho-ІкB (p-ІкB) or phospho-MEK (p-MEK) activity upon 6-MP treatment. Band intensity was quantified by densitometry and normalized to actin levels. The lower left panels show IKB or MEK protein expression upon azathioprine and 6-MP treatment. Band intensity was normalized to ERK2 levels. The right panels show Rac1 and vav protein expression upon azathioprine and 6-MP treatment. Azathioprine and 6-MP treatment had little effect on Rac1 protein levels, whereas vav levels were increased in cellular extracts. Band intensity was quantified by densitometry and normalized to ERK2 levels. Den, densitometry. (c) 6-MP induces vav accumulation. $\mathrm{CD}^{+} \mathrm{T}$ lymphocytes were stimulated in the presence or absence of azathioprine, 6-MP, or 6-TG for 5 days. Cells were immunostained with Rac1-specific antibodies and vav-specific antibodies and Cy3-labeled secondary antibodies (red). Nuclei were counterstained with Hoechst blue. Confocal microscopy showed that the expression of the Rac1-associated guanosine exchange factor vav was increased upon treatment with azathioprine and its metabolites, whereas Rac1 levels were nearly unchanged.

known to prevent $\mathrm{T}$ cell apoptosis upon CD28 costimulation, and azathioprine and its metabolites suppress this activation pathway.

To exclude a general inhibitory effect of azathioprine and its metabolites on the activation of GTPases, we next determined the activation of Ras that is known to occur upon CD3/TCR stimulation of $\mathrm{T}$ cells. It was found that the activation of Ras was virtually unaffected (Figure 7c), suggesting a specific inhibition of Rac1 activation by azathioprine. This marked specificity pointed to the potential direct binding of an azathioprine metabolite to Rac1. Indeed, we were able to detect 6-TG in Rac1 pull-downs from primary $T$ cells upon azathioprine treatment (approximately $120 \mathrm{pg}$ of 6-TG per microgram), suggesting that azathioprine-generated 6-Thio-GTP can directly bind to Rac1 in vivo. Consistently, 6-Thio-GTP was able to bind to recombinant Rac1 under in vitro conditions (although with lower affinity than GTP) (Figure 7e). Furthermore, 6-ThioGTP did not significantly compete with GTP for recombinant Ras, suggesting that 6-Thio-GTP may bind to selected GTPases only.

Taken together, these data suggest that azathioprine and its metabolites target CD28-mediated signaling in primary $\mathrm{T}$ cells by specifically suppressing the activation of the GTPase Rac1 through 6-Thio-GTP, leading to a mitochondrial pathway of apoptosis (Figure 8).

\section{Discussion}

In the present study, we have identified a unique and unexpected role for azathioprine and its metabolites in the control of $\mathrm{T}$ cell apoptosis by modulation of Rac1 activation upon CD28 costimulation. Specific block- 
a

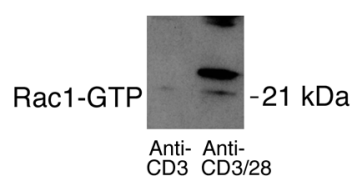

C Anti-CD3/28

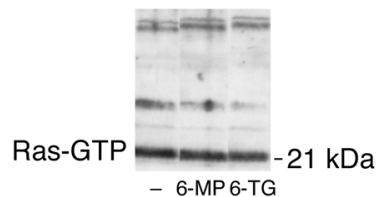

b

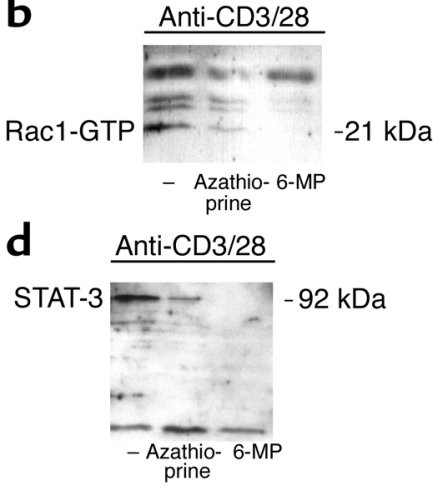

e

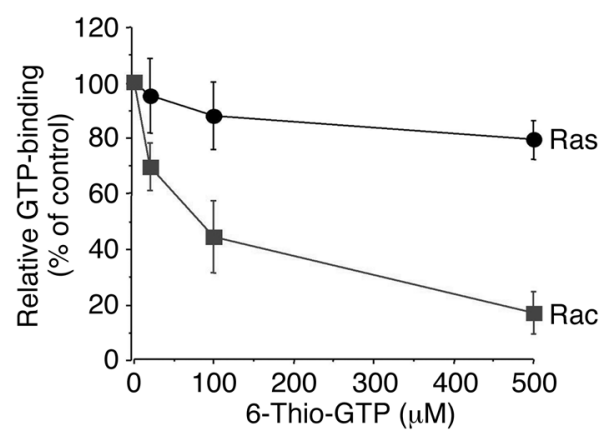

Figure 7

(a) Rac1 activation assay in activated primary T cells. Purified CD4+ T lymphocytes were stimulated with IL-2 and antibodies to CD3 or IL-2 plus antibodies to CD3 and CD28 for 3 days. GTP-bound Rac1 (Rac1-GTP) was analyzed using PAK to determine Rac1 activation. CD28 costimulation led to induction of Rac1 activation in primary T cells. (b) Azathioprine and 6-MP suppress Rac1 activation. Purified CD4+ T lymphocytes were stimulated in the presence or absence of azathioprine or 6-MP for 3 days, as indicated. GTP-bound Rac1 was analyzed using PAK to determine Rac1 activation. Azathioprine treatment led to a reduction of CD28-dependent Rac1 activation. One representative experiment out of five is shown. (c) 6-MP and 6-TG fail to modulate Ras activation. GTP-bound Ras (Ras-GTP) was analyzed using Raf RGD to determine Ras activation. Azathioprine and its metabolites did not affect Ras activation. One representative experiment of three is shown. (d) Downregulation of STAT-3 in primary T cells upon treatment with azathioprine or 6-MP. Purified CD4+ T lymphocytes were stimulated in the presence or absence of azathioprine and 6-MP for 3 days, as indicated. Since Rac1 binds and activates STAT-3 (53), GTP-bound Rac1 was obtained using PAK, and STAT-3 levels were determined by immunoblotting. (e) Competition of GTP binding to Rac1 or Ras by 6-Thio-GTP. Recombinant Rac1 or Ras was incubated with radiolabeled GTP ([ $\left.\left.{ }^{3} \mathrm{H}\right] \mathrm{GTP}\right)$ and increasing amounts of chemically synthesized 6-Thio-GTP (0-500 $\mu$ M). Next, Rac1 was obtained using PAK-1 agarose, followed by analysis of $\left[{ }^{3} \mathrm{H}\right]$ GTP-bound Rac1 by scintillation counting. Similarly, Ras was obtained using Raf RGD agarose followed by analysis of [ $\left.{ }^{3} \mathrm{H}\right] \mathrm{GTP}$-bound Ras by scintillation counting. 6-Thio-GTP led to a concentration-dependent suppression of [ $\left.{ }^{3} \mathrm{H}\right]$ GTP-bound Rac1 but had little effect on [ $\left.{ }^{3} \mathrm{H}\right] \mathrm{GTP}$-bound Ras.

ade of Rac1 activation is achieved by azathioprine-generated 6-Thio-GTP that binds to Rac1 instead of GTP. Consecutively, the activation of Rac1 target genes such as MEK, NF- $\mathrm{KB}$, and bcl- $\mathrm{x}_{\mathrm{L}}$ is suppressed by azathioprine, leading to a mitochondrial pathway of apoptosis. Azathioprine thus converts a costimulatory signal into an apoptotic signal by modulating Rac1 activity. These findings may explain the beneficial immunosuppressive effects of azathioprine and have important implications for the design of novel specific therapies for organ transplantation and autoimmune diseases.

Since unchecked proliferation of lymphocytes may provoke the risk of developing chronic inflammatory or autoimmune diseases, the immune system controls effi-

\section{Figure 8}

A model for azathioprine-mediated immunosuppression. Hypothetical mechanism of the action of azathioprine in primary $\mathrm{CD} 4^{+} \mathrm{T}$ cells upon CD28 costimulation. In normal T cells, CD28 costimulation leads to vav activation, causing replacement of the Rac1-bound GDP with GTP (62). Activated Rac1 in turn leads to activation of the MEKK/IKB/NF-KB pathway and STAT-3 activation, both of which result in enhanced $b c l-x_{\llcorner}$levels. Augmented bcl- $x_{\llcorner}$levels then provide an important antiapoptotic signal. Azathioprine and its metabolites 6MP and 6-TG specifically target Rac1 activation by the generation of 6-Thio-GTP, which binds to Rac1. Blockade of Rac1 activation leads to suppression of bcl- $x_{L}$ expression through inhibition of STAT-3 and NF- $\kappa B$ activation, followed by a mitochondrial pathway of apoptosis. MAP, mitrogen-activated protein; IKB, inhibitor of NF- $\kappa B$. IKK, I $\mathrm{I} B$ kinase; MAPKK; MAPK kinase; MAP3K, MAPKK kinase. cient elimination of activated lymphocytes in a process known as apoptosis $(44,54)$. This is particularly important for the mucosal immune system, since a resistance of lamina propria cells to apoptosis may lead to chronic inflammatory responses in the gut (45). We provide evidence here that azathioprine, a drug that has been used for decades for successful treatment of IBD, induces $\mathrm{T}$ cell apoptosis (particularly of CD45RO memory $\mathrm{T}$ cells). Since CD45RO T lymphocytes are considered to be

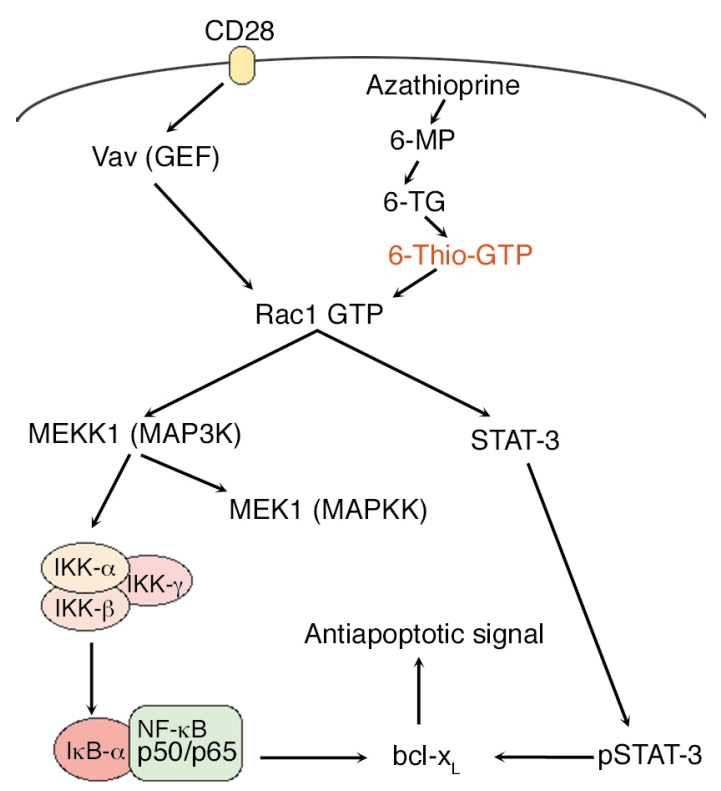


key effector cells in IBD, one may speculate that the excellent therapeutic efficacy of azathioprine in these diseases could be due to the induction of local $\mathrm{T}$ cell apoptosis. This hypothesis is supported by the finding that successful azathioprine treatment in patients with IBD leads to an increased number of apoptotic $T$ cells in the peripheral blood and the lamina propria. This mechanism of action based on apoptotis induction of activated $\mathrm{T}$ cells would also explain why azathioprine is effective in both Crohn disease and ulcerative colitis, although both diseases seem to have a different pathogenesis and are associated with a different $T$ cell cytokine profile $(31,32,45)$. The induction of apoptosis by azathioprine was critically dependent on $\mathrm{T}$ cell costimulation with CD28, which is known to inhibit TCR-induced apoptosis during a primary $\mathrm{T}$ cell response by activation of the antiapoptotic bcl- $x_{\mathrm{L}}$ protein $(55,56)$. Interestingly, azathioprine downregulates bcl- $x_{\mathrm{L}}$ expression at the mRNA and protein levels, strongly suggesting that this drug blocks a key regulatory pathway in CD28 signaling. The fact that azathioprine regulates $\mathrm{bcl}-\mathrm{x}_{\mathrm{L}}$ expression would suggest that azathioprine regulates a mitochondrial pathway of apoptosis. Indeed, we observed that azathioprine-mediated apoptosis led to downregulation of the mitochondrial membrane potential and could be suppressed by a specific inhibitor of caspase-9.

We next analyzed the MEK/NF-KB signaling pathway that is known to induce bcl- $\mathrm{x}_{\mathrm{L}}$ expression upon CD28 costimulation in primary $T$ cells (49). It was found that azathioprine and its metabolites suppressed MEK and

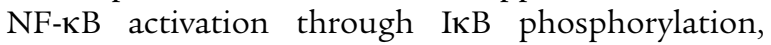
although IкB and MEK protein levels were nearly unaffected. These data suggested that the suppression of the MEK/NF- $\mathrm{KB}$ signaling pathway by azathioprine is mediated by an unexpected specific mechanism involving an azathioprine metabolite rather than by azathioprineinduced suppression of protein production. Indeed, we observed that the azathioprine metabolite 6-Thio-GTP directly binds to Rac1, a Rac GTPase that is known to play a key role in CD28 signaling and MEK/NF-KB activation in T cells (57-59). Furthermore, the levels of vav1, a CD28-responsive guanosine exchange factor for Rac1 whose activity is suppressed by the adapter protein Cb1-b (50-52), were upregulated by azathioprine treatment. This finding is consistent with a compensatory upstream mechanism to achieve Rac1 activation in primary $T$ cells upon administration of azathioprine.

Rac proteins play a major role in $\mathrm{T}$ cell development, differentiation, and proliferation (58-60). Whereas dominant positive Rac mutations have been associated with increased cell proliferation and tumors, functionally inactive Rac mutations are associated with immunodeficiencies in humans (61). Azathioprine-mediated suppression of Rac1 activation in $\mathrm{T}$ cells was mediated by direct binding of an azathioprine metabolite (6-ThioGTP) to Rac1 instead of GTP. Although the precise mechanism by which binding of 6-Thio-GTP suppresses Rac1 activation in T cells remains to be determined, the function of another GTPase (Ras) was not inhibited by azathioprine and its metabolites. Our data are thus consistent with a model in which the specificity of the 6-Thio-GTP-induced blockade of Rac1 function is related to the structure of the Rac1 protein. In any case, azathioprine specifically blocked the Rac1-mediated activation of NF-KB and STAT- 3 in primary $T$ cells that mediate bcl- $\mathrm{x}_{\mathrm{L}}$ activation upon $\mathrm{CD} 28$ costimulation and therefore provide an important antiapoptotic signal in anti-CD28-stimulated T lymphocytes (Figure 8). The CD28 signaling pathway, however, is not only important for the initial activation of $T$ cells but also for maintaining their viability and responsiveness during a persistent immune response $(38,56)$. Azathioprine-induced suppression of CD28 signaling events may be particularly important for the mechanism of action of this drug, since it is frequently used in chronic inflammatory diseases in which repeated antigen-specific stimulation of effector $T$ cells occurs and in which elimination of effector $\mathrm{T}$ cells is needed $(33,45)$. Consistent with this idea, we observed that azathioprine can also induce apoptosis of T lymphocytes that were preactivated with CD28.

Taken together, our data identify a unique and novel molecular mechanism of action of azathioprine on the basis of the suppression of Rac1 activation. Further studies showed that azathioprine-induced suppression of Rac1 activation leads to suppression of bcl- $\mathrm{x}_{\mathrm{L}}$ expression (through blockade of NF- $\kappa$ B and STAT-3 activation) and a mitochondrial pathway of $\mathrm{T}$ cell apoptosis. Our data thus suggest that azathioprine-induced immunosuppression is mediated by suppression of Rac1 activation and the consecutive induction of $\mathrm{T}$ cell apoptosis. It should be noted, however, that azathioprine-induced apoptosis affects mainly CD45RO effector $\mathrm{T}$ cells upon costimulation with $\mathrm{CD} 28$, suggesting that azathioprine may be particularly effective in eliminating pathogenic memory $\mathrm{T}$ cells in autoimmune and chronic inflammatory diseases. These data have important implications for the design of novel and more specific therapies for autoimmune diseases. In particular, 6-Thio-GTP derivates with higher affinity to Rac1 may be useful to achieve more powerful immunosuppression in autoimmune diseases and organ transplantation.

\section{Acknowledgments}

M.F. Neurath was supported by grants from the Deutsche Forschungsgemeinschaft (Ne 490/4-1 and Sonderforschungsbereich 548, 432, 490) and the Gerhard Hess program of the Deutsche Forschungsgemeinschaft (Ne 490/3-1) and is a recipient of a Fullbright scholarship. R. Blumberg was supported by NIH grants DK44319, DK51362, and DK53056 and the Harvard Digestive Diseases Center. H. Walczak was supported by the BioFuture Program of the Bundesministerium für Bildung und Forschung.

\footnotetext{
1. McGeown, M., et al. 1988. Ten-year results of renal transplantation with azathioprine and prednisolone as only immunosuppression. Lancet. 1:983-991.

2. Andreone, P.A., et al. 1986. Reduction of infectious complications following heart transplantation with triple-drug immunotherapy. J. Heart Transplant. 5:13-19.
} 
3. British and Dutch Multiple Sclerosis Azathioprine Trial Group. 1988. Double-masked trial of azathioprine in multiple sclerosis. Lancet. 2:179-186. 4. DeSilva, M., and Hazleman, B.L. 1981. Long-term azathioprine in rheumatoid arthritis. A double-blind study. Ann. Rheum. Dis. 40:560-568.

5. Ginzler, E., Sharon, E., Diamond, H., and Kaplan, D. 1975. Long term maintenance therapy with azathioprine in systemic lupus erythematosus. Arthritis Rheum. 18:27-35

6. Christensen, E., et al. 1985. Beneficial effect of azathioprine and prediction of prognosis in primary biliary cirrhosis. Final results of an international trial. Gastroenterology. 89:1084-1091.

7. Candy, S., et al. 1995. A controlled double blind study of azathioprine in the management of Crohn's disease. Gut. 37:674-678.

8. Bouhnik, Y., et al. 1996. Long-term follow-up of patients with Crohn's disease treated with azathioprine or 6-mercaptopurine. Lancet. 347:215-219.

9. D’Haens, G., Geboes, K., Ponette, E., Penninckx, F., and Rutgeerts, P. 1997. Healing of severe recurrent ileitis with azathioprine therapy in patients with Crohn's disease. Gastroenterology. 112:1475-1481.

10. Lewis, J.D., Schwartz, J.S., and Lichtenstein, G.R. 2000. Azathioprine for maintenance of remission in Crohn's disease: benefits outweigh the risk of lymphoma. Gastroenterology. 118:1018-1024.

11. Present, D.H., et al. 1980. Treatment of Crohn's disease with 6-mercaptopurine: a long-term randomized, double-blind study. N. Engl. J. Med. 302:981-987.

12. Bean, R.H.D. 1962. The treatment of chronic active ulcerative colitis with 6-mercaptopurine. Med. J. Aust. 2:592-593.

13. Dimitriu, A., and Fauci, A.S. 1978. Activation of human B lymphocytes. XI. Differential effects of azathioprine on B lymphocytes and lymphocyte subpopulations regulating B cell function. J. Immunol. 121:2335-2339.

14. Lennard, L. 1992. The clinical pharmacology of 6-mercaptopurine. Eur. J. Clin. Pharmacol. 43:329-335.

15. Röllinghoff, M., Schrader, J., and Wagner, H. 1973. Effect of azathioprine and cytosine arabinoside on humoral and cellular immunity in vitro. Clin. Exp. Immunol. 15:261-269.

16. Abdou, N.I., Zweiman, B., and Casella, S.R. 1973. Effects of azathioprine therapy on bone marrow-dependent and thymus-dependent cells in man. Clin. Exp. Immunol. 13:55-64.

17. Bach, M.A., and Bach, J.F. 1972. Activities of immunosuppressive agents in vitro. II. Different timing of azathioprine and methotrexate in inhibition and stimulation of mixed lymphocyte reaction. Clin. Exp. Immunol. 11:89-98.

18. Hoffmann, M., Rychlewski, J., Chrzanowska, M., and Hermann, T. 2001. Mechanism of activation of an immunosuppressive drug: azathioprine. Quantum chemical study on the reaction of azathioprine with cysteine. J. Am. Chem. Soc. 123:6404-6409.

19. Kroplin, T., and Iven, H. 2000. Methylation of 6-mercaptopurine and 6-thioguanine by thiopurine S-methyltransferase. A comparison of activity in red blood cell samples of 199 blood donors. Eur. J. Clin. Pharmacol. 56:343-345.

20. Van Os, E.C., et al. 1996. Azathioprine pharmacokinetics after intravenous, oral, delayed release oral and rectal foam administration. Gut. 39:63-68.

21. Podolsky, D.K. 1991. Inflammatory bowel disease. N. Engl. J. Med. 325:928-937.

22. Beutler, B. 2001. Autoimmunity and apoptosis: the Crohn's connection. Immunity. 15:5-14.

23. Neurath, M.F., Finotto, S., and Glimcher, L.H. 2002. The role of Th1/Th2 polarization in mucosal immunity. Nat. Med. 8:567-573.

24. MacDonald, T.T., Monteleone, G., and Pender, S.L.F. 2000. Recent developments in the immunology of inflammatory bowel disease. Scand. J. Immunol. 51:2-9.

25. Shanahan, F. 2002. Crohn's disease. Lancet. 359:62-69.

26. Hugot, J.P., et al. 2001. Association of NOD2 leucine-rich repeat variants with susceptibility to Crohn's disease. Nature. 411:599-603.

27. Ogura, Y., et al. 2001. A frameshift mutation in NOD2 associated with susceptibility to Crohn's disease. Nature. 411:603-606.

28. Targan, S.R., et al. 1997. A short-term study of chimeric monoclonal antibody cA2 to tumor necrosis factor alpha for Crohn's disease. N. Engl.J. Med. 337:1029-1035

29. Elson, C.O., Sartor, R.B., Tennyson, G.S., and Riddell, R.H. 1995. Experimental models of inflammatory bowel disease. Gastroenterology. 109:1344-1367.

30. Atreya, R., et al. 2000. Blockade of IL-6 trans-signaling suppresses T cell resistance against apoptosis in chronic intestinal inflammation: evidence in Crohn's disease and experimental colitis in vivo. Nat. Med. 6:583-588.

31. Breese, E., Braegger, C.P., Corrigan, C.J., Walker-Smith, J.A., and MacDonald, T.T. 1993. Interleukin-2 and interferon-gamma secreting T cells in normal and diseased human intestinal mucosa. Immunology. 78:127-131.

32. Plevy, S.E., et al. 1997. A role for TNF-alpha and mucosal T helper-1 cytokines in the pathogenesis of Crohn's disease. J. Immunol. 159:6276-6282.

33. Boirivant, M., et al. 1999. Lamina propria T cells in Crohn's disease and other gastrointestinal inflammation show defective CD2 pathway-induced apoptosis. Gastroenterology. 116:557-565.

34. Sandborn, W.J., et al. 1999. Lack of effect of intravenous administration on time to respond to azathioprine for steroid-treated Crohn's disease. Gas troenterology. 117:527-535.

35. Pearson, D.C., May, G.R., Fick, G.H., and Sutherland, L.R. 1995. Azathioprine and 6-mercaptopurine in Crohn disease. A meta-analysis. Ann. Intern Med. 123:132-142.

36. Ewe, K., et al. 1993. Azathioprine combined with prednisolone or monotherapy with prednisone in active Crohn's disease. Gastroenterology. 105:367-376.

37. Holtmann, M.H., et al. 2002. Tumor necrosis factor-receptor 2 is upregulated on lamina propria $\mathrm{T}$ cells in Crohn's disease and promotes experimental colitis in vivo. Eur. J. Immunol. 32:3142-3151.

38. Noel, P.J., Boise, L.H., Green, J.M., and Thompson, C.B. 1996. CD28 co-stimulation prevents cell death during primary $\mathrm{T}$ cell activation J. Immunol. 157:636-647.

39. Radvanyi, L.G., et al. 1996. CD28 costimulation inhibits TCR-induced apoptosis during a primary T cell response. J. Immunol. 156:1788-1798.

40. Khoshnan, A., et al. 2000. The NF- $\kappa \mathrm{B}$ cascade is important in Bcl- $\mathrm{x}_{\mathrm{L}}$ expression and for the antiapoptotic effects of the CD28 receptor in primary human $\mathrm{CD}^{+}$lymphocytes. J. Immunol. 165:1743-1754.

41. Jodo, S., et al. 2000. CD95 (Fas) ligand-expressing vesicles display antibodymediated, FcR-dependent enhancement of cytotoxicity. J. Immunol. 165:5487-5494.

42. Nicoletti, I., Migliorati, G., Pagliacci, M.C., Grignani, F., and Riccardi, C. 1991. A rapid and simple method for measuring thymocyte apoptosis by propidium iodide staining and flow cytometry. J. Immunol. Methods. 139:271-279.

43. Finotto, S., et al. 2001. Treatment of allergic airway inflammation and hyperresponsiveness by local antisense-induced blockade of GATA-3 expression. J. Exp. Med. 193:1247-1260.

44. Scaffidi, C., Kirchhoff, S., Krammer, P.H., and Peter, M.E. 1999. Apoptosis signaling in lymphocytes. Curr. Opin. Immunol. 11:277-285.

45. Neurath, M.F., et al. 2001. Regulation of T-cell apoptosis in inflammatory bowel disease: to die or not to die, that is the mucosal question. Trends Immunol. 22:21-26.

46. Cuffari, C., Seidman, E.G., Latour, S., and Theoret, Y. 1996. Quantification of 6-thioguanine in peripheral blood leukocyte DNA in Crohn's disease patients on maintenance 6-mercaptopurine therapy. Can. J. Physiol. Pharmacol. 74:580-585.

47. Zamzami, N., et al. 1995. Reduction in mitochondrial potential constitutes an early irreversible step of programmed lymphocyte death in vivo. J. Exp. Med. 181:1661-1672.

48. Kirchhoff, S., Müller, W.W., Li-Weber, M., and Krammer, P.H. 2000. Up-regulation of c-FLIPshort and reduction of activation-induced cell death in CD28-co-stimulated human T cells. Eur. J. Immunol. 30:2765-2774.

49. Tuosto, L., et al. 2000. Mitogen-activated kinase kinase kinase 1 regulates $\mathrm{T}$ cell receptor and CD28-mediated signaling events which lead to NF- $\kappa \mathrm{B}$ activation. Eur. J. Immunol. 30:2445-2454.

50. Chiang, Y.J., et al. 2000. Cbl-b regulates the CD28 dependence of T-cell activation. Nature. 403:216-220.

51. Krawczyk, C., et al. 2000. Cbl-b is a negative regulator of receptor clustering and raft aggregation in T cells. Immunity. 13:463-473.

52. Raab, M., Pfister, S., and Rudd, C.E. 2001. CD28 signaling via VAV/SLP-76 adaptors: regulation of cytokine transcription independent of TCR ligation. Immunity. 15:921-933.

53. Simon, A.R., et al. 2000. Regulation of STAT3 by direct binding of the Rac1 GTPase. Science. 290:144-147.

54. Lenardo, M., et al. 1999. Mature T lymphocyte apoptosis - immune regulation in a dynamic and unpredictable antigenic environment. Annu. Rev Immunol. 17:221-253.

55. Boise, L.H., Noel, P.J., and Thompson, C.B. 1995. CD28 and apoptosis. Curr. Opin. Immunol. 7:620-625.

56. Mueller, D.L., Seiffert, S., Fang, W., and Behrens, T.W. 1996. Differential regulation of bcl-2 and bcl-x by CD3, CD28, and the IL-2 receptor in cloned $\mathrm{CD}^{+}$helper T cells. A model for the long-term survival of memory cells J. Immunol. 156:1764-1771.

57. Marinari, B., et al. 2002. Vav cooperates with CD28 to induce NF-кB activation via a pathway involving Rac-1 and mitogen-activated kinase kinase 1. Eur. J. Immunol. 32:447-456.

58. Gomez, M., Tybulewicz, V., and Cantrell, D.A. 2000. Control of pre T cell proliferation and differentiation by the GTPase Rac1. Nat. Immunol. 1:348-352.

59. Joneson, T., and Bar-Sagi, D. 1999. Suppression of Ras-induced apoptosis by the Rac GTPase. Mol. Cell. Biol. 19:5892-5901.

60. Li, B., et al. 2000. Role of the guanosine triphosphate Rac2 in Thelper 1 cell differentiation. Science. 288:2219-2222.

61. Williams, D.A., et al. 2000. Dominant negative mutation of the hematopoietic-specific Rho GTPase, Rac2, is associated with a human phagocyte immunodeficiency. Blood. 96:1646-1654

62. Kaga, S., Ragg, S., Rogers, K.A., and Ochi, A. 1998. Activation of p21CDC42/Rac-activated kinases by CD28 signaling: p21-activated kinase (PAK) and MEK kinase 1 (MEKK1) may mediate the interplay between CD3 and CD28 signals. J. Immunol. 160:4182-4189. 